\title{
BIRTHDAYS, SCHOOLING, AND CRIME: NEW EVIDENCE ON THE DROPOUT-CRIME NEXUS
}

\author{
Philip J. Cook \\ Songman Kang \\ Working Paper 18791 \\ http://www.nber.org/papers/w18791
NATIONAL BUREAU OF ECONOMIC RESEARCH
1050 Massachusetts Avenue
Cambridge, MA 02138
February 2013

We thank Peter Arcidiacono, Ken Dodge, V. Joseph Hotz, Jens Ludwig, Hugh Macartney, Justin McCrary, Seth Sanders, and Chris Timmins as well as participants at the 2012 Association for Public Policy and Management Conference for helpful comments. This research was supported with funds from Duke University. The views expressed herein are those of the authors and do not necessarily reflect the views of the National Bureau of Economic Research.

NBER working papers are circulated for discussion and comment purposes. They have not been peerreviewed or been subject to the review by the NBER Board of Directors that accompanies official NBER publications.

(C) 2013 by Philip J. Cook and Songman Kang. All rights reserved. Short sections of text, not to exceed two paragraphs, may be quoted without explicit permission provided that full credit, including $\odot$ notice, is given to the source. 
Birthdays, Schooling, and Crime: New Evidence on the Dropout-Crime Nexus

Philip J. Cook and Songman Kang

NBER Working Paper No. 18791

February 2013

JEL No. I21,K42

\begin{abstract}
Based on administrative data for five cohorts of public school children in North Carolina, we demonstrate that those born just after the cut date for starting school are likely to outperform those born just before in reading and math in middle school, and are less likely to be involved in juvenile delinquency. On the other hand, those born after the cut date are more likely to drop out of high school before graduation and commit a felony offense by age 19 . We also present suggestive evidence that the higher dropout rate is due to the fact that youths born after the cut date have longer exposure to the legal possibility of dropping out. The "crime" and "dropout" differences are strong but somewhat muted by the fact that youths born just before the cut date are substantially more likely to be held back in school. We document considerable heterogeneity in educational and criminal outcomes by sex, race and other indicators of socioeconomic disadvantage.
\end{abstract}

Philip J. Cook

Sanford School of Public Policy

Duke University

215 Sanford Building

Durham, NC 27708-0245

and NBER

pcook@duke.edu

Songman Kang

Sanford School of Public Policy

Duke University

Durham, NC 27708

sk92@duke.edu. 


\section{Introduction}

Laws governing school attendance have a well-documented effect on educational attainment, and hence may plausibly influence involvement in criminal activity. Under a standard economic model of crime (Becker 1968; Ehrlich 1973), education increases the stock of human capital and hence creates higher earnings potential from legitimate work, but has less effect on the rewards to criminal activity. Since work and crime are to some extent substitutes, participation in criminal activity would tend to decline as the relative payoff to legitimate activities increases. Education may also influence individual choices through other channels, including the makeup of the peer group. Association with peers who are attending school (rather than dropouts) may have a positive influence to the extent that they, relatively speaking, tend to value success in licit activities or to lack crime-specific skills.

Convicts as a group have less education than their peers, and high-school dropouts are greatly over represented among criminals (Harlow 2003; Raphael and Sills 2008; Lochner 2011). Recent empirical evidence offers support for a causal interpretation of this association. Particularly strong evidence derives from reforms in compulsory schooling laws in the United States, Great Britain, and Sweden: extensions of the mandatory schooling age in these countries resulted in an increase in educational attainment and reduction in lifetime involvement in criminal activity (Lochner and Moretti 2004; Anderson 2009; Hjalmarsson, Holmlund and Lindquist 2011; Machin, Marie and Vujic 2011; Clay, Lingwall, and Stephens 2012). ${ }^{1}$

We take another approach to the same end in this paper. We use as a source of variation in the probability of dropout the interaction between the child's birthdate and the minimum schoolentry age. A series of articles beginning with Angrist and Krueger (1991) have analyzed the effects of birth date on academic achievement, graduation, earnings, and other outcomes. This literature focuses on state laws specifying the age at which a child may begin kindergarten. In North Carolina, for example, until recently the law specified that a child had to be at least 5 years

\footnotetext{
${ }^{1}$ Relatedly, Jacob and Lefgren (2003) and Luallen (2006) find that there are immediate crime effects of being in school, namely that juvenile involvement in property crime is reduced during school days, while violent crime rates are increased.
} 
old on or before October $16^{\text {th }}$ to be eligible to enter kindergarten. ${ }^{2}$ The result is that a child born on October $17^{\text {th }}$ could not start until a year after a child born on October $16^{\text {th }}$. This type of discontinuity can provide the empirical basis for a strong quasi-experimental analysis of the effects of age on school careers. Unsurprisingly, the children who are required to delay entry into school tend to perform better than their younger grade-level peers. On the other hand, there is some evidence that students who start school late due to their birth date are less likely to complete high school. A simple explanation is that they have greater exposure to the legal opportunity to drop out. In North Carolina, where the school leaving age is just 16, a youth who was born on October $17^{\text {th }}$ and went through school on time would have 31 months of "exposure" to the possibility of dropping out before graduation, whereas a youth born a day earlier would have just 19 months. For students with a relatively weak commitment to school, the extra year of exposure may spell the difference between graduating and dropping out.

Our analyses are based on rich administrative data from the North Carolina public school system and other state agencies. In addition to detailed data on enrollment and academic performance, the data set includes items from the youth's birth certificate, juvenile delinquency and adult criminal records. Using the regression discontinuity (RD) framework (Thistlethwaite and Campbell 1960), we compare educational and criminal outcomes of children born just before and after the school entry cutoff date. Given that individual characteristics associated with educational and criminal outcomes are balanced at the cutoff date, the differences in outcomes provide estimates of the causal effect of school entry eligibility on education and crime. The data set is large and of high quality - for example, exact birth dates and data on demographic characteristics are taken directly from the birth certificates, while education and crime data are taken from administrative records rather than self-report.

Our study contributes to the existing literature by replicating and extending findings on the effect of entry age on academic performance, grade retention, and dropout. Unlike earlier contributions to this literature, which for the most part employ Decennial Census Data, our data set tracks individual students. Our approach here is to treat the entry eligibility in the spirit of "intention to treat" in an experiment, thus avoiding the potential confounding effect of the endogenous choice

\footnotetext{
${ }^{2}$ The law was revised in 2009, now requiring that a child had to reach age 5 on or before August $31^{\text {st }}$ to be eligible to enter kindergarten.
} 
by parents or school officials to hold back a child. Our results are therefore not relevant to evaluating "academic redshirting," in which parents delay sending their children to school hoping that greater maturity will help them better succeed in school. Although we briefly explore the extent to which individuals' criminal outcomes are influenced by variation in school entry timing (the "treatment on the treated" effect), our main objective is to estimate the causal effect of providing one group of students school entry eligibility nearly a year earlier than another group of comparable students. Given that parents do not exercise precise control over children's birthdates near the cutoff date, our identifying variation in school entry eligibility at the cutoff date may be "as good as randomized" (Lee and Lemieux 2010).

Our results provide strong evidence that older youths continue to perform relatively well in middle school, and confirm that they nonetheless are more likely to depart school before graduation. A breakdown by sex and race indicates considerable heterogeneity in these results. In particular, we find large differences in the likelihood of being "on time" - males born just before the cutoff are more likely than females to be held back either by parents or school officials, with the result that the discontinuity in the grade level configuration at October $17^{\text {th }}$ is smaller for males and declines from one year to the next. The result is to mute the effect of the "experimental" intervention to the extent that for males the birthdate ends up causing little difference in exposure to the dropout option. That explains our finding that females are much more likely to drop out of high school if born after the cutoff date, whereas there is little difference in dropout rates for males. The effects are also heterogeneous with respect to sociodemographic characteristics. We find strong eligibility effects on high school dropout among groups of children traditionally considered disadvantaged - those who were born out of wedlock and whose mothers had less than high school education at the time of birth.

We go on to present new empirical evidence on school-entry eligibility and crime, finding that youths born just after the cutoff have a significantly lower likelihood of criminal activity between age 13 and 15 (as measured by delinquent complaints), but a higher likelihood of committing a serious adult crime (as measured by felony conviction for crimes committed by age 19). Combined with our finding of a higher dropout rate for those born after the cutoff date, it is reasonable to conclude that high school dropout enhances the risk of committing serious crimes. 
That inference is strengthened by the fact that the elevated crime rate for the delayed-entry group is concentrated at age 19, by which time most youths are no longer in school.

The rest of the paper is organized as follows. Section 2 provides a brief review of the relevant literature. Section 3 describes the institutional background and data used. Sections 4 and 5 introduce our empirical strategy and present the main results. Section 6 discusses the validity and robustness of our empirical strategy and findings. Section 7 explores the link between the time "exposure" to legal dropout and the probability of dropping out. Section 8 concludes.

\section{Literature Review}

Other things equal, older students do better in the classroom. Older students are likely to be more mature than their classmates, and hence better prepared for the challenges of learning new material and managing relationships with other students and adults. The positive link between students' relative age and academic achievement has been documented in a number of recent papers (Bedard and Dhuey 2006; Datar 2006; Puhani and Weber 2007; McEwan and Shapiro 2008; Elder and Lubotsky 2009; Black, Devereux and Salvanes 2011; Clay, Lingwall, and Stephens 2012).

If this early advantage is reinforced over time through positive-feedback processes, including enjoyment of school, the positive regard of teachers, and academic tracking, then it may persist and even expand over time. The possibility that the early advantage of being old for grade may have persistent impacts on students' educational experiences has convinced some parents to delay enrolling their children for a year. This practice of "academic redshirting" has gained popularity in recent years, and is considered an important aspect of the "lengthening of childhood" (Deming and Dynarski 2008). It is more common for boys than girls, and for whites than African Americans.

On the other hand, the early academic advantage associated with the extra year of age may dissipate in later years if positive feedback processes are not strong and the maturity gap associated with an extra year of age diminishes. Indeed, Elder and Lubotsky (2009) find evidence that the relative age effect on academic achievement is present in the beginning of kindergarten, but that the disparity in reading and math test scores between older and younger 
students mostly disappears by the time students reach grade 8. By contrast, Bedard and Dhuey (2006) find that relative age effects on math and science test scores remain large in grade 8.

In spite of the advantages associated with relative maturity on academic achievement, there is a real possibility that late entry to school may adversely affect individuals' life outcomes.

Research shows that students relatively old for their grade are less likely to complete high school. Under the compulsory schooling laws of the states, students are eligible to leave school after reaching a threshold age, ranging from 16 to 18, and students who are old for their grade have a longer period during which they can legally drop out prior to graduation. Angrist and Krueger (1991) were the first to document this negative relationship between students' educational attainment and relative age of entry. They used national Decennial Census data which included quarter of birth and self-reported educational attainment; those born in the fourth quarter had slightly more schooling than those born in the first quarter, which (together with a claim that those born in the fourth quarter could typically start school earlier than those born in the subsequent first quarter) they treated as the result of the school-entry date. The authors report that those born in the fourth quarter also had relatively high earnings while in their 40s, suggesting a positive return to education.

The Angrist-Krueger study, while seminal, was based on available data which did not include exact birth dates. In contrast, two recent studies were able to utilize more detailed data. Dobkin and Ferreira (2010) examine outcomes for American children born just before and after the school entry cutoff date. They utilized detailed Decennial Census data for residents of California and Texas; using a regression-discontinuity design and exact birthdate, they demonstrated that students whose birthdate allowed them to start school relatively early were more likely to graduate, but were also more likely to be retained in grade; remarkably, the authors find no evidence that the age at which children enter school affects job market outcomes. This null result, because it is based on superior data, is probably more trustworthy than the positive result of Angrist and Krueger.

McCrary and Royer (2011) adopt a similar approach to investigating the relative age effect for females. They use the Natality Detail Files for Texas and California, finding that birthdate relative to the cutoff date for entry had no effect on subsequent childbearing (up through age 24). However, they used the "schooling" item on the birth certificates to demonstrate that women 
who started school later (born after the cutoff) tended to have less education at the time they had their first child. They found little effect on infant health. The surprising conclusion from the McCrary and Royer study, as well as the Dobkin and Ferreria study, is that while the birthdate does have a causal effect on completed schooling, it has little or no effect on outcomes often associated with schooling - wages, fertility, and healthy pregnancies.

In contrast, policy interventions that increase the length of compulsory schooling have unambiguously positive findings. Reforms of this sort have strong, positive effects on individuals' outcomes in mortality (Lleras-Muney 2005), earnings (Oreopoulos 2006; Clay, Lingwall, and Stephens 2012) and, of particular interest here, crime (Lochner and Moretti 2004; Anderson 2009; Hjalmarsson, Holmlund and Lindquist 2011; Machin, Marie and Vujic 2011).

To our knowledge, our paper presents the first empirical evidence that the variation in educational attainment induced by the minimum age requirement for school entry has consequences for crime. Our identifying variation, namely, whether students were born just before or after the school entry cutoff, yields estimates that can be interpreted as causal effects of being offered school entry eligibility nearly a year earlier than a comparable control group. Our analyses complement existing research on the effect of changing the length of compulsory schooling on crime, but the interventions are different in important respects. First, an increase in the school-leaving age not only influences the probability of dropout for any one student, but also affects the composition of the student body attending high school, which may have important consequences on labor market conditions for the affected cohorts. In contrast, our "experiment" holds constant the composition of the student body and focuses on the relative age of individual students who are all subject to comparable labor market conditions and criminal justice environment. Furthermore, an increase in the school-leaving age keeps youths in school for an additional year of their adolescence, a time when youths are gaining autonomy and presented with a variety of temptations. In contrast, the entry cutoff does not directly affect whether youths spend, say, their $17^{\text {th }}$ year in school.

\section{Institutional Framework and Data Description}

\subsection{Minimum Age Requirement for School Entry in North Carolina}


The compulsory schooling law in North Carolina specifies the minimum age of enrollment in public kindergarten. ${ }^{3}$ While the law has been recently amended, prior to the 2009 school year a child in North Carolina became eligible to enter kindergarten only if he reached the age of five by October 16 in the relevant year. Thus the children born in September 1987 were eligible to enter school a year earlier than those born in November 1987, who were in turn slated to enter school at the same time as children born in September 1988.

The actual distribution of students across grades is complicated by other features of law and practice. First, state law allows private kindergarten programs to establish their own policies regarding the minimum age at which children are eligible to enter. ${ }^{4}$ A child who started at age 4 in a private kindergarten could then transfer to the public school system and be placed in first grade a year later. Second, the minimum age requirement for school entry does not apply to students who attended kindergarten from a different state in accordance with the rules of that state before moving to the North Carolina public school system. Lastly, although all public school systems in North Carolina have to offer kindergarten, kindergarten attendance is not required. ${ }^{5}$ Children may skip kindergarten and enter school in first grade, which is not subject to the minimum age requirement as in the kindergarten entry. However, the age distribution observed among public school students in various grade levels, presented in more detail below, demonstrates that the number of students placed in grade levels higher than predicted by their birthdates is extremely small.

A more substantial qualification to our results is that some parents choose to delay their child's enrollment in school by a year, and other students are retained in primary school for an extra year by school officials. The prevalence of such delays is particularly large among children born just before the cutoff date. Thus, our findings are best interpreted as intention-to-treat (ITT) effects, namely, the effect on educational and criminal outcomes of receiving school entry eligibility nearly a year earlier than a comparable control group, rather than the effect of actually entering school a year earlier. However, for certain subgroups of students with low rates of academic

\footnotetext{
${ }^{3}$ North Carolina General Statutes 115C-364.

${ }^{4}$ In case of movement from non-public schools to public schools after the kindergarten year, principals in public schools have the authority to place students in appropriate grade levels. ${ }^{5}$ Public school laws in North Carolina only require students to attend school from the ages of seven to sixteen.
} 
redshirting and grade retention, the ITT estimates can be close approximations to the effects of school entry timing. We explore this issue further when examining potential heterogeneity in the school eligibility effects across different demographic groups with varying degrees of academic redshirting.

\subsection{Data Description}

Our main data source is individual-level administrative data from the North Carolina public school system, provided by the North Carolina Education Research Data Center (NCERDC). The student-level data from the NCERDC cover all students enrolled in the North Carolina public school system, and contain detailed information on students' schooling from grades 3 to 12. Our measure of academic achievement comes from students' performance on state-wide End-of-Grade (EOG) reading and math tests that are administered from grades 3 to 8, which all students are required to take. Students' test performance across years can be tracked by unique individual identifiers assigned by the NCERDC. EOG test records specify the grade in which they were administered; we identify students who take the EOG tests for a given grade level more than once as grade repeaters. Enrollment data in North Carolina public school system between grade levels between 3 and 12 are also available from the NCERDC “masterfile”. A potential difficulty in following students' academic progress over time is the movement of students between the public school system and private schools in North Carolina, or migration to and from other states. If the group of students leaving or entering the North Carolina public school system is systematically different from those initially enrolled and staying in the system in characteristics related to their academic performance, it is not straightforward to track and understand students' academic progress over time. For instance, in comparing academic performance of students born before and after the school entry cutoff date, if students who were born just after the cutoff date and score high on EOGs are more likely to leave for private schools, the difference in academic achievement between those born before and after the cutoff who remain in the public schools will diminish over time even if the true effect of school entry eligibility remains constant. Alternatively, comparison of educational experience at the cutoff date over time may be obscured by the influx of new students into the public school system. For example, students entering North Carolina public schools after kindergarten years may include disproportionately many children from immigrant households with limited English proficiency. 
To avoid these potential complications, we restrict our main analyses to students who were born in North Carolina and enrolled in the North Carolina public school system for five consecutive years between ages 11 and 15 . $^{6}$ This choice is further motivated by the data availability and the compulsory schooling laws in North Carolina allowing students to leave school at age $16 .^{7}$

We determine students' in-state birth status from North Carolina birth certificate data, which are merged with the educational data via the NCERDC individual identifiers. The birth certificate data also provide information on the exact date of birth, a key identifying variation in our empirical analyses below. ${ }^{8}$ In addition, the birth certificate data contains other key demographic attributes measured at the time of birth, such as gender, mother's race, parents' marital status, mother's education attainment and age level, and birth weight. Our analyses focus on students born within 120 days of school entry cutoff dates. The 120-day window covers students born between June 19 of the given year and February 14 of the following year. ${ }^{9}$ Since the EOG tests are administered in late May to early June, students from a given birth cohort (e.g., those born within 120 days of the school entry cutoff date in 1987) are of the same age when taking the EOG tests, which makes it straightforward to construct and interpret some of our outcome measures, such as grade level distribution at a given age level. In our regression analyses, several alternatives for time windows around the cutoff date are considered. We compare educational and criminal outcomes of students born within 10 days, 30 days and 60 days of the cutoff date and find comparable results. (See Section 6.)

\footnotetext{
${ }^{6}$ We also exclude students enrolled in charter schools from our analysis.

${ }^{7}$ We also ran alternative analyses based on 1) all North Carolina public school students enrolled in the North Carolina public school system between ages 11 and 15 (regardless of their birthplace) and 2) those who were born in North Carolina and moved into or out of the public school system between ages 13 and 15. Results are available on request from the authors.

${ }^{8}$ The EOG test score files from the NCERDC data also contain students' date of birth, but aggregated up to each calendar month. For example, all students who were born in October 1987 are assigned October 15, 1987 as their birthdates. Since the school entry cutoff date in North Carolina we use is in the middle of a calendar month (October 17), the EOG test score files does not allow us to distinguish students born just before and after the cutoff date.

${ }^{9}$ The birth-certificate data linked with students' educational data is available from 1987-2007. The 1987-1988 cohorts are chosen so that academic outcomes from earlier years (e.g., grade level in age 11) and longer-term life outcomes (e.g., criminal between age 17 and 19) can both be examined from the same cohorts. Similarly, due to data availability, the 1991-1993 cohorts are the only cohorts whose academic outcomes and juvenile delinquency patterns can be both examined.
} 
We use the following measures of students' educational experience: students' EOG reading and math test score percentiles in grades 6 through 8, grade retention between ages 11 and 15, grade at age 11 and age 15, and school enrollment 4 years after grade 8 . A student's grade at a particular age is determined from the EOG test-score files. Students who took the EOG for the same grade in two consecutive years are designated as "repeaters.” We do not have direct information on high school graduation for our sample of students, but for the earlier cohort we do know whether they persisted in public school. In particular, we consider whether students remain enrolled in North Carolina public schools 4 years after $8^{\text {th }}$ grade (henceforth, "'Year 12"). Year 12 is equivalent to grade 12 if they did not repeat grades between grades 8 and 12 . Students who transfer out of state or to a private school after age 15 are, unfortunately, indistinguishable from dropouts by this measure. It is also true that some students who are enrolled in Year 12 never graduate. The net effect is that Year 12 enrollment appears to overstate the graduation rate: Year 12 enrollment for our sample is 79 percent, while the official 4-year high school graduation rate in North Carolina during School Year 2007-2008 was 70 percent.

Table 1 presents descriptive statistics of our sample. The first two columns correspond to students born within 120 days (first column) and 60 days (second column) of the school entry cutoff date in 1987 and 1988, and the next two columns provide comparable information for students born in 1991, 1992 and 1993. As will be made clear below, the 120 day-window will be used for our graphical analyses, and the 60-day window for our regression analyses. ${ }^{10}$ Due to the data availability issue, some of the covariates and outcome measures are available for either 1987-1988 or 1991-1993 cohorts only. In particular, Year 12 enrollment and adult criminal conviction measures are available for 1987-1988 cohorts only, while free-and-reduced-pricelunch eligibility and juvenile-delinquency data are available for 1991-1993 cohorts only.

There is little difference in the observable characteristics across sample cohorts (1987-1988 vs. 1991-1993). A number of demographic characteristics taken from birth certificates are similar: sex (about 50-50), race (30 percent black), mother's age and education at birth (10 percent below

${ }^{10}$ To be more specific, given our choice of a 60-day bandwidth, our local linear regression attributes zero weights to data points outside the 60-day window from the cutoff date. Thus, data points that are exactly 60 days away from the cutoff date also carry zero weight in the regression analysis. 
18, and 12 percent who were older but had not graduated from high school) and birth weight (7 percent small enough to be problematic by the conventional cut point of 2500 grams).

Consistent with the change in family structure over time, however, the share of births to unwed mothers is noticeably higher among 1991-1993 cohorts than 1987-1988 cohorts (33 percent vs. 26 percent). For the 1991-1993 cohorts, we also have information on students' free/reduced price lunch eligibility at age 11, obtained from their EOG test records, and find that 44 percent were eligible.

The EOG reading and math test score percentiles, normalized with respect to all students who take the tests in a given grade level for a given school year, are close to 50 across all three grade levels considered. This finding suggests that our sample of North Carolina natives is comparable with the general North Carolina public school student population in terms of academic performance in middle years. Finally, we consider students' grade retention and Year 12 school enrollment. The rate of grade retention between ages 11 and 15 is 8 percent for 1987-1988 cohorts and 5 percent for 1991-1993 cohorts. Among 1987-1988 cohorts, 79 percent of students remain enrolled in school in Year 12, which is to say four years after they were enrolled in $8^{\text {th }}$ grade.

\section{[Table 1]}

Our measures of criminal activity are based on the official juvenile complaint ${ }^{11}$ and adult-felonyconviction data in North Carolina, provided by the North Carolina Department of Juvenile Justice and Delinquency Prevention (NCDJJDP) and North Carolina Department of Corrections (NCDOC) respectively. We examine whether individuals receive a juvenile complaint between ages 13 and 15 and whether they are convicted of a serious crime committed between ages 17 and 19. ${ }^{12}$ The incidence of juvenile complaints between ages 13 and 15 in our 1991-1993 sample is 9 percent, and that of convictions for adult criminal activity between ages 17 and 19 is

\footnotetext{
${ }^{11}$ A complaint filed by a law enforcement officer, teacher or citizen against a youth suspected of committing a crime/delinquency is the first step of the juvenile justice system. After evaluating the complaint and evidence, a NCDJJDP counselor determines whether the case should go to court and makes referral to other resources if necessary.

${ }^{12}$ The choice of crime outcome measures is driven by data availability. For example, for the 1987 (1988) cohort, we can only observe their conviction outcomes between ages 17 and 20 (ages 16 and 19).
} 
6 percent. While the official complaint and felony conviction records are reliable indicators of involvement in crime, they are far from comprehensive. For example, for a youth to be convicted of a serious crime requires that the crime is known to the police and results in an arrest, and that the resulting case works its way through the court system to conviction at the felony level. It is fair to say that our indicator tends to signal the high end of the crimeinvolvement spectrum.

\section{Empirical Strategy}

Our empirical strategy exploits the sharp discontinuity in grade level configuration between children born before and after the school entry cutoff date in North Carolina. Figure 1 illustrates the extent of this grade level variation among sample students born within 120 days of the cutoff date in 1987. Each panel shows the age at which students take the EOG tests and the corresponding grade level distribution, computed separately for students born before and after the cutoff date. For example, our 1987 cohort was 11 years old when taking their EOG tests in School Year 1998-1999; 75 percent of students born before the cutoff were enrolled in grade 6, while more than 90 percent of those born after were in grade 5. Similarly large differences in grade level configuration between students born before and after the cutoff date are also observed in subsequent years, as shown.

\section{[Figure 1]}

The grade level variation at the cutoff date enables an estimate of the causal effects of school entry eligibility on children's subsequent educational and criminal outcomes. Given that other characteristics associated with these outcomes remain comparable and continuous at the cutoff date, the outcomes of children born just before the cutoff provide reasonable estimates of the counterfactual outcomes of those born just after the cutoff had they been eligible to enter school a year earlier. This interpretation of regression discontinuity estimates using the potential outcomes framework is formalized in Hahn, Todd and Van der Klaauw (2001). Moreover, as long as individuals do not have precise control over their children's birthdates, the variation in school entry eligibility can be considered as good as randomized near the cutoff date (Lee and Lemieux 2010). Below, we formally introduce our regression specification and describe our estimation procedure in more detail. 


\subsection{Regression Specification}

The discontinuity in educational and criminal outcomes at the cutoff date can be estimated by imposing a global parametric structure, e.g., the following equation with quadratic polynomials:

$\mathrm{Y}_{\mathrm{i}}=\alpha_{1} \mathrm{D}_{\mathrm{i}}+\alpha_{2} \mathrm{R}_{\mathrm{i}}+\alpha_{3} \mathrm{D}_{\mathrm{i}} \mathrm{R}_{\mathrm{i}}+\alpha_{4} R_{i}^{2}+\alpha_{5} \mathrm{D}_{\mathrm{i}} R_{i}^{2}+\mathrm{X}_{\mathrm{i}} \beta+\varepsilon_{\mathrm{i}}$

where $D_{i}$ is a binary indicator equal to 1 if student $i$ was born after the cutoff date of October 16, and $\mathrm{R}_{\mathrm{i}}$ represents the distance between student i's birthday and the cutoff date. For example, $\mathrm{R}_{\mathrm{i}}$ is equal to 0 for a student born on October 16, 5 for a student born on October 21 and -5 for a student born on October 11. $\mathrm{D}_{\mathrm{i}} \mathrm{R}_{\mathrm{i}}$ is an interaction term between the distance from the cutoff date and a post-cutoff birthday indicator. A squared term of $R_{i}$ and its interaction with $D_{i}$ are also included in the specification. $\mathrm{X}_{\mathrm{i}}$ is a vector of observable characteristics which may be associated with the outcomes of interest, and includes information on gender, race, out-of-wedlock birth, mother's educational attainment and age at the time of birth, and birth weight. $\varepsilon_{\mathrm{i}}$ represents idiosyncratic errors at the individual level. Each birth date has several hundred observations; we cluster standard errors at the birthday level.

Alternatively, we can use the local-linear-regression technique which estimates the discontinuity non-parametrically, assigning more weight to data points closer to the cutoff date than points further away. Local-linear-regression estimates can be obtained by solving the following method-of-moment specification:

$\min \sum_{i=1}^{N i}\left(Y_{i}-\alpha_{1} D_{i}-\alpha_{2} R_{i}-\alpha_{3} D_{i} R_{i}\right)^{2} K_{h}\left(D_{i}, R_{i}\right)$

where $K_{h}\left(D_{i}, R_{i}\right)$ represents a weighting kernel function with bandwidth $\mathrm{h}$. We use the following triangular kernel in our analyses, as it is known to be optimal for local-linear regression at the boundary (Fan and Gijbels 1992):

$K_{h}\left(D_{i}, R_{i}\right)=1-\frac{1-\left|R_{i}\right|}{h} 1\left\{\left|R_{i}\right|<1\right\}$.

The vector of individual covariates $\mathrm{X}$ is included in the specification to improve the precision as follows:

$\min \sum_{i=1}^{N i}\left(Y_{i}-\alpha_{1} D_{i}-\alpha_{2} R_{i}-\alpha_{3} D_{i} R_{i}-X_{i} \beta\right)^{2} K_{h}\left(D_{i}, R_{i}\right)$ 
We ran the regression analyses using both global parametric specification (Equation (1)) and local linear regression (Equation (3)), and obtained very similar results. For brevity, we only report point estimates obtained from local linear regression, which has attractive bias properties (Fan and Gijbels 1992). In our graphical illustration of the discontinuities at the cutoff date, however, we depict raw data points with lines showing local linear smoother and quadratic fits, which should correspond to the estimation results from the local linear regression and global parametric approach, respectively.

From Equation (3), it is clear that the local linear regression estimates are affected by the choices of the kernel and bandwidth. The consensus in the technical literature is that the choice of the kernel has little impact on the estimates, but the choice of bandwidth is more influential. In the absence of the widely accepted rule of bandwidth choice in local linear regression estimation, we have tried a number of alternative bandwidth choices in our regression analyses. ${ }^{13}$ In an empirical setting similar to ours, McCrary and Royer (2011) use bandwidths of 50 and 70 days when comparing women born before and after the school entry cutoff date in California and Texas. Alternatively, the “Rule-of-Thumb’ bandwidth choice method proposed by Fan and Gijbels (1992) suggests bandwidths between 7 and 26 days for our outcomes of interest. We first present our main results using a 60-day bandwidth, similar to the bandwidth choice made by McCrary and Royer (2011). In Section 6, we describe in more detail the optimal bandwidth for our data, and examine the robustness of our findings across alternative bandwidth choices.

\section{Results}

We begin by demonstrating that the minimum entry age created a sharp discontinuity in the grade level around October $17^{\text {th }}$. The grade level distribution at age 11 is depicted in Figure 2 . The horizontal axis corresponds to students' birth dates relative to the school entry cutoff date (day 0 = October 17). Dots represent grade levels in which students were enrolled when taking the End-of-Grade tests at age 11. Solid curves correspond to local linear smoother based on a triangle kernel and 60-day bandwidth, and dashed curves represent quadratic fits.

[Figure 2] 
The discontinuity is clear: those who were born just before the cutoff average 0.6 grade level higher than those born just after. That the difference is less than a full year indicates that a large share of students born before the cutoff date either entered kindergarten after their eligibility year or repeated a grade prior to age 11.

Table 2 presents point estimates of the grade level discontinuity at the cutoff date. Panel (A) corresponds to the estimates from 1987-1988 cohorts and Panel (B) corresponds to 1991-1993 cohorts. The first column presents estimates from a baseline specification in which grade level at age 11 is regressed on an indicator of birth date after the cutoff (D), the birthdate (R), their interaction (DR) and a constant (Equation (2)). Consistent with the graphical evidence, we find a sizable discontinuity at the cutoff date in the grade levels at age 11. The second column shows estimates from a specification that includes additional individual covariates (Equation (3)). In support of the assumption that the timing of birth near the cutoff date is independent of sociodemographic characteristics, we find little change on the key coefficient estimates, but a considerable increase in explanatory power and some improvement in estimate precision. The results for the covariates are of some interest in their own right: in particular, they indicate that blacks and women are relatively likely to have reached this stage "on time," other things equal. (As discussed below, blacks as a group are actually more likely to be held back at every stage; that effect is reversed in this regression due to confounding effect of several of the covariates.)

Results from the 1991-93 cohorts, presented in the next two columns, tell a similar story. The grade-level variation at age 11 is again close to 0.6 , and the estimate changes little when additional covariates are introduced to the specification, including free/reduced price lunch eligibility at age 11 .

The lower panel of Table 2 reports results for all the same regressions but for grade level at age 15. The discontinuity in the grade level is somewhat smaller, reflecting the differential retention rates between younger and older students.

\section{[Table 2]}

Next, we consider the discontinuity in students' academic achievement levels at the cutoff date. Figures 3 and 4 show the distribution of the test score percentiles from EOG reading and math tests from grades 6, 7, and 8. As above, solid and dashed curves represent local linear smoother 
and quadratic fits, respectively. Children born just after the cutoff are likely to score higher in both reading (Figure 3) and math (Figure 4) across all three grade levels. Table 3 presents local linear regression estimates of the reading achievement percentile discontinuity at the cutoff date. The first three columns present estimates from the 1987-1988 cohorts, and correspond to the EOG reading achievement in grades 6, 7, and 8. For brevity, we only report estimates from an extended specification that controls for additional individual characteristics. However, the discontinuity estimates obtained from a baseline specification (Equation (2)) and an extended specification (Equation (3)) are very similar. We find that individuals born just after the cutoff score substantially higher on EOG reading tests across Grades 6-8. The next three columns show the corresponding estimates obtained from 1991-1993 cohorts. The discontinuity in the reading percentile at the cutoff is similar to those obtained from the 1987-1988 cohort. Estimates from both samples show that the magnitude of the discontinuity decreases over time, yet remains significantly large across all three grade levels. To put this number into perspective, the magnitude of the post-cutoff coefficient (D) is approximately 75 percent of that on out-ofwedlock birth, and more than twice as large as that on underweight birth. Note that our results are consonant with those reported by Bedard and Dhuey (2006), who also find a persistent advantage in math test scores through middle school.

[Figures 3 and 4, and Table 3]

\section{Promotion and Persistence}

To a considerable extent, the school entry eligibility age influences whether 1) students successfully advance through the grade levels on time between ages 11 and 15 and 2) students remain enrolled in school in Year 11 and 12 (which we define as three or four years after grade 8 respectively). Students born before the cutoff date are relatively likely to be held back. Figure 5 demonstrates this phenomenon by showing the likelihood of repeating a grade between ages 11 and 15. Moreover, Figure 6 shows that students born after the cutoff are more likely to leave school before graduation. The North Carolina compulsory schooling law allows students to drop out from school at age 16. A student born just after the cutoff will be exposed to the legal possibility of dropping out prior to graduation for almost a year longer than a student born just before, assuming neither has been delayed. Table 4 presents the corresponding regression estimates. Among both 1987-1988 and 1991-1993 cohorts, students born just after the cutoff 
date are 6 percentage points less likely to repeat a grade between ages 11 and 15 . On the other hand, we find a 4 percentage point drop in the Year 12 enrollment at the cutoff from the 19871988 cohorts. Table 4 also presents the results for Year 11, defined as enrollment three years following $8^{\text {th }}$ grade. It is of interest that the effect of a post-cutoff birthday is only half as large for this outcome, suggesting that the "extra” dropouts are concentrated in that fourth year - as would be expected by the exposure hypothesis.

Again, coefficients on the individual covariates take expected signs. Children who were born out of wedlock, whose mothers were underage or had low education attainment, and who had low birth weight are significantly more likely to repeat grades and are less likely to remain enrolled in high school before graduation. Free/reduced price lunch eligibility is a significant and positive predictor of grade retention outcome among 1991-1993 cohorts. We take a closer look at the potential heterogeneity in educational experience and the magnitude of the discontinuity at the cutoff date across different demographic groups below.

[Table 4 and Figures 5 and 6]

Juvenile Delinquency and Adult Crime

Our main objective is to explore how the differences in educational experience, driven by the variation in the timing of birth with respect to the school entry cutoff date, influence individuals' risks in delinquency and crime. For this purpose, we examine the following measures: 1) juvenile delinquency committed between ages 13 and 15, measured by the NCDJJDP complaint records, and 2) adult crime, defined by committing a crime while aged 17, 18, or 19, that results in a felony conviction.

Consider Table 5, which presents the estimation results on juvenile delinquency obtained from the 1991-1993 cohorts. The first column shows that, on average, children born just after the cutoff are 3 percentage points less likely to be involved in juvenile delinquency between ages 13 and 15. The next three columns break down the juvenile delinquency outcome by age level. We find a statistically significant drop at the cutoff date in delinquent complaints at ages 14 and 15 . It is noteworthy that the discontinuity at the cutoff remains large even after many of the key individual characteristics are controlled for. Specifically, the magnitude of the discontinuity in 
total juvenile delinquency, a 3 percentage point drop, is similar to the coefficients on out-ofwedlock births and having a underage mother (4 percentage point each).

The distribution of juvenile complaint rates around the cutoff date closely resembles that of measures of academic achievement examined earlier. Importantly, we find that children born just after the cutoff date not only outperform those born just before in academic achievement and grade progress, but also are less likely to be involved in juvenile delinquency. One potential explanation is that children who do well in the classroom are likely to enjoy school more and hence resist the temptation to play truant with delinquent friends. Alternatively, those with little success in schoolwork may anticipate low potential earnings from legitimate labor market, where academic success and educational attainment are much valued, and instead “invest” more on building crime capital.

\section{[Table 5]}

Adult criminal participation may be influenced by academic success and persistence, which in our results push in opposite directions. ${ }^{14}$ On the one hand, we find that children born just after the cutoff date show higher academic achievement and lower risks of juvenile delinquency, which are associated with low likelihoods of committing a crime as adults. On the other hand, they are also more likely to drop out, which has adverse impact on their subsequent risk of criminal activity. The sign and magnitude of the discontinuity in the adult criminal risks at the cutoff should then depend on the magnitudes of these two opposing factors.

Table 6 reports estimation results for adult crime committed between ages 17 and 19. The first column shows that children born just after the cutoff are 0.9 percentage points more likely to commit a crime between ages 17 and 19. The discontinuity in the crime outcome at the cutoff date is marginally significant and relatively small. However, the increase in adult crime at the cutoff is particularly noteworthy, given that those born just after had significantly lower rates of juvenile delinquency (Table 5). A likely explanation is that the adverse effect of high school dropout on crime is large enough to outweigh the crime-reducing effects of early academic advantage and low juvenile delinquency. Indeed, the fact that the eligibility effect on crime

\footnotetext{
${ }^{14}$ In North Carolina, individuals who commit a crime at or above age 16, which coincides with the minimum school leaving age in the state, are tried as adults.
} 
between 17 and 19 is concentrated in the crime committed at age 19 (fourth column) suggests that high school dropout, most of which take place before age 19, may be an important mechanism through which the variation in school entry eligibility influences adult crime.

[Table 6]

Table 7 presents descriptive statistics which reiterate the potential causal link between high school completion and adult crime. Consider the first column. Among our main estimating sample, i.e., those born within 60 days of the school entry cutoff date in 1987 and 1988, 95\% of students remain enrolled in school at age 16 and $89 \%$ at age 17 . Nearly $80 \%$ of them are either enrolled in school at age 18 or reach $12^{\text {th }}$ grade. The next three columns correspond to the school enrollment rates of individuals who commit crime at age 17,18 , and 19. The distribution of enrollment rates across these groups is consistent with the causal effect of high school dropout on crime; the rate of school enrollment at age 17 is noticeably lower among individuals who commit crime at age 18 and 19 (70\%). Similarly, those who commit crime at age 17 have the lowest rate of enrollment at age 16 enrollment rate (82\%).

\section{[Table 7]}

As a matter of curiosity, we also analyzed the teenage birthrate for females in our sample, and found that the school entry age had no discernible effect. That finding accords with McCrary and Royer's (2011) finding on the likelihood of giving birth by age 24; they found that age of school entry age had no effect on the birth rate, although it did affect the educational attainment at the time of birth.

\section{Heterogeneity across Demographic Groups}

It turns out that there are large differences by race and sex when it comes to school careers. Females are more likely to be on schedule -- placed in the grade level predicted by their birthdate -- than males, and for both sexes whites are more likely on schedule than blacks. The largest drop in the on-time rate is for black males, where it declines from $75 \%$ at age 11 to just $61 \%$ at 
age 15 (the last year before legal drop out). ${ }^{15}$ Figure 7 depicts the pattern during these years for the four race-sex groups.

\section{[Figure 7]}

The RD results for the four race-sex groups are summarized in the first four columns of Table 8. The top panel corresponds to estimates from the 1987-1988 cohorts and the bottom panel to the 1991-1993 cohorts. Sample means specific to each demographic groups are presented in square brackets. Some of the outcome measures, such as Year 12 enrollment, juvenile delinquency and adult crime, are available only from either 1987-1988 or 1991-1993 samples. On the other hand, estimation results on grade retention and on-time progress at age 15 are available for both cohorts and virtually identical across the two samples.

\section{[Table 8]}

For all four groups, the younger students are more likely to be retained in grade at least once between 11 and 15. The largest effect by far is for black males, where the "extra” retentions amount to $12 \%$ of the total. For white women, the effect is only about $3 \%$. The RD results for grade progress at age 15 demonstrate the remarkable extent to which retention erases the discontinuity created by school entry age. At age 15, the white males born after the cut date are 52 to 55 percentage points more likely to be on time (other things equal); for black males the difference is 30 to 32 percentage points. The average grade level for white males is just 0.3 years higher for the group born just before the cutoff. Perhaps as a result, the likelihood of reaching Year 12 (rather than dropping out) is not much different for males born on either side of the cut point. For females, the difference is 6 to 8 percentage points, a significant effect both statistically and substantively. Considering criminal outcomes, we find a significant drop in the rates of juvenile delinquency at the cutoff for all four race-sex groups, but the effects on adult crime are smaller. The coefficients on crime committed at age 19 are, however, positive for all four groups.

${ }^{15}$ Dobkin and Ferreira (2010, p. 52) report that in Texas and California blacks are less likely to be held back than whites. The contradiction with our results may be due to the fact that they are using the self-report data on grade from the Census, rather than administrative data. 
In Table 9, we restrict our analyses to three demographic groups traditionally considered to be disadvantaged: children born to unwed mothers, or whose mothers had less than high school education, and children who were eligible for free/reduced price lunch program at age 11 . All three groups have higher rates of grade retention, high school dropout, juvenile delinquency and adult crime committed than the overall population, making them highly policy-relevant groups. Within these subgroups, we find that the RD effects on grade retention, high school dropout, juvenile delinquency and adult crime are much larger than those obtained from the general population. We again find the estimates from two samples closely resemble each other.

\section{[Table 9]}

\section{Validity}

An attractive property of the regression-discontinuity framework is that, as long as individuals do not have precise control over the running variable, which assigns individuals to a treatment or control group, the variation in the treatment is "as good as randomized in a neighborhood around the discontinuity threshold" (Lee and Lemieux 2010). The prevalence of academic redshirting indicates that some parents prefer to have their children enter school older rather than younger. But, since children who were born just before the cutoff can readily delay school entry for a year, there is little incentive for parents to manipulate children's birthdates near the cutoff date. A related possibility is that age eligibility for entering a public kindergarten may influence parents' decision to send their children to private schools instead of public school. For example, our RD estimates will be muted if wealthier parents are more likely to send their children to private kindergarten when born just after the cutoff dates and then keep them there from age 11 to 15 . (Recall that if they are in private school during that period, they will not be included in our sample.)

Figures 8 and 9 present birth frequencies, measured by the number of births recorded in the state birth certificate, and the rate of sample attrition, defined by the number of individuals in our estimating sample divided by the overall birth frequency, averaged across the five cohorts we consider. In the top panel, we observe some evidence of seasonal effects on the birth frequency, but no noticeable discontinuity at the cutoff date. More importantly, there is little evidence of discontinuity in the rate of sample attrition around the cutoff date (bottom panel). These figures 
suggest that our variation in school entry eligibility is unlikely to be obscured by a systematic manipulation of the timing of birth or use of private schools relative to the cutoff date.

[Figures 8 and 9]

Another way to examine the validity of our research design is to compare the individuals' observed characteristics across the cutoff date. If the variation in individuals' timing of birth near the cutoff date is effectively random, we should expect that individuals on both sides of the cutoff date are similar in their observable characteristics. Indeed, the continuity of individual covariates at the discontinuity threshold is considered a key identifying assumption of a valid regression discontinuity design (Hahn, Todd and van der Klaauw 2001). This assumption also enables a clear interpretation of regression discontinuity estimates in the potential outcomes framework. If individuals born just before and after the cutoff date closely resemble each other in all relevant characteristics except their school entry eligibility, educational and criminal outcomes of children born just after the cutoff provide a natural counterfactual for children born just before the cutoff date. We test for the continuity of observable characteristics at the cutoff using our preferred regression specification (3) and report the results in Table 10. The estimation results show that the discontinuity at the cutoff is small and insignificant for all covariates considered, for both 1987-1988 and 1991-1993 samples.

[Table 10]

\section{Robustness}

It is easy to see from Equation (2) that our RD estimates are sensitive to the choice of bandwidth. Allowing a larger bandwidth enables us to employ more observations in the analyses, which would improve the precision of the estimates. On the other hand, if the bandwidth is overly wide, local linear approximation may not be a good fit for the data in hand. The optimal bandwidth choice should then depend on the sample size and the extent to which the sample distribution is approximated by a linear function near the cutoff point. Although researchers have proposed various techniques for optimal bandwidth choice in recent years (Fan and Gijbels 1996; Ludwig and Miller 2007; Imbens and Lemieux 2008; Imbens and Kalyanaraman 2012), there does not appear to be a clear consensus. Therefore, to examine the degree to which our estimates are sensitive to the choice of bandwidth, we replicate the regression analyses with 
alternative choices of bandwidths, ranging from 10 days to 60 days. The bandwidth of 10 days is motivated by the "Rule-of-Thumb" (ROT) method proposed by Fan and Gijbels (1996), where the optimal bandwidth depends on the fourth-order global polynomial fit of the data points and its curvature near the cutoff point. Appendix Table A.1 reports the list of the ROT results for the selected outcome measures.

Table 11 presents estimation results. Shown in each column are the discontinuities in outcome measures at the cutoff date based on the given bandwidth choice. Although the magnitudes differ across bandwidth choices, the discontinuities in educational experience and criminal risks mostly remain large and significant. It is unlikely that our findings are mainly driven by a particular choice of bandwidth.

[Table 11]

\section{Exposure to Legal Dropout, High School Attainment and Crime}

One potential explanation for the lower rate of high school attainment for children born after the cutoff date, in spite of their earlier academic advantage on standardized tests and grade retention, is that children who are relatively old for their grades have a longer time window during which they are eligible to drop out from high school. For instance, in North Carolina where students may leave school at age 16 or above, children who were born on the cutoff date and did not delay school entry or repeat grades have approximately 19 months between their 16th birthday and high school graduation, compared to 31 months for children born the day after the cutoff.

The RD analysis reported above is in the spirit of the "intention to treat" approach, recognizing that the "treatment" is greatly attenuated by high rates of grade retention for the younger group. To estimate the "effect of the treatment on the treated" in this case, we re-estimate the Year 12 and crime RD equations for the subsample that stayed on time at least through age 11, and hence were fully exposed to the "treatment." The problem, of course, is that for this selected sample, the treatment is not orthogonal to student characteristics. In particular, we expect that the younger students are more "selected" -- mature and academically gifted (relative to their peer group) -- than is true for the older students. Our usual covariates may not fully account for this 
difference. Our new estimate adds the students' standardized EOG reading score from age 11 to control for the academic disparity between pre- and post-cutoff students. ${ }^{16}$

Table 12 presents the estimation results. Consider the first three columns, which pertain to the 1987-1988 cohorts. When comparing the outcomes of students who entered school and experienced on-time progress to the appropriate grade level, we find strong discontinuities in the Year 12 enrollment and criminal conviction at the cutoff date (first and second columns). Among on-timers, children who were born just after the cutoff date are more than 10 percentage points less likely to remain enrolled in school in Year 12 and about 1 percentage point more likely to become felons, even after the academic disparity is controlled for. When these estimates are compared with the "ITT" estimates obtained from the full sample (third column), the Year 12 effects appear over twice as large for the "on time" sample as for the full sample. The crime coefficients obtained from the on-timers are also about 20\% larger than the corresponding ITT estimate.

\section{[Table 12]}

On the other hand, when considering the juvenile delinquency outcome from the 1991-1993 cohorts, we find little difference across on-timers and full sample. This finding should not be surprising, as the difference in exposure to legal dropout opportunity should only influence individuals' high school dropout and adult crime outcomes, but not criminal involvement taking place before school-leaving age. Moreover, given that the "on-time" and "ITT" estimates closely resemble each other, regardless of whether the age-11 EOG reading score is controlled for, the potential complication due to selection may not be that severe in practice.

Lastly, it may be worthwhile to compare our estimates on high school persistence with previous research. Using empirical frameworks similar to ours, Dobkin and Ferreira (2010) report

\footnotetext{
${ }^{16}$ We standard-normalize the EOG reading score with respect to the score distribution from a given school year, instead of a given school year and grade level. For example, when constructing the standardized EOG reading score at age 11 for the 1987 cohort, we normalize students' test scores to mean 0 and variance 1, with respect to all EOG reading scores from grades 3 to 8, recorded in School Year 1988-1999. This across-grade normalization process is made possible by a unique feature of the NC EOG tests, in which its "developmentally-scaled scores are intended to be interpreted much like measurements of height in inches" (Pommerich et al., 1993; North Carolina State Board of Public Instruction 1996), enabling researchers to compare test scores across different grades.
} 
individuals who were born just after the school entry cutoff date in California (Texas) are 0.6 (0.8) percentage points more likely to complete 12th grade. McCrary and Royer (2011)’s analyses on female samples in California and Texas find that mothers who were born just after the cutoff date in California have fewer years of schooling completed than those born just before, by 0.14 in California and 0.24 in Texas. Our finding of a 4 percentage point difference in Year 12 enrollment is much higher. We offer two plausible explanations for this discrepancy. First, the higher school leaving age in California and Texas attenuates the differences in the length of exposure to legal dropout opportunities between students born before and after the cutoff date. While North Carolina students born just before and after the cutoff date have 19 and 31 months between their school leaving age (16) and high school graduation, the corresponding numbers are 0 and 7 months for California and Texas students, where the minimum school leaving age is 18. Second, our measure of educational attainment is directly obtained from administrative records in North Carolina public school system, and thus may contain more accurate information than self-reported education attainment data used by Dobkin and Ferreira (2010) and McCrary and Royer (2011).

\section{Conclusion}

In this paper, we exploit the discontinuity in school entry age created by a legal minimum age requirement to investigate the effects of relative age at entry on the relationship between schooling and crime. Utilizing administrative data on birth, school, and crime from the North Carolina Education Research Data Center, we find that youths born after the cutoff age are typically older than their classmates and tend to do better in school: their end-of-grade test scores are higher in middle school, and they are less likely to be retained in grade between ages 11 and 15. They have lower rates of delinquency between ages 13 and 15. On the other hand, the delayed-entry group is also more likely to drop out and be convicted of serious crimes committed by age 19. These effects are quite heterogeneous by sex, race, and other indicators of socioeconomic disadvantage. In particular, the tendency to "redshirt" students or retain them in grade is stronger for males than females, which mutes the "dropout” effect for that group by shrinking the age gap. We also find sizable discontinuities in educational and criminal outcomes at the cutoff from children who were born to unwed mothers, whose mothers had low education attainment and who were eligible for reduced/free price lunch. 
This paper is the first to document an effect of relative age at school entry on crime involvement. Other recent assessments have found little or no effect of relative age on other outcomes, including fertility and earnings, despite the finding that school entry age affects school achievement and the likelihood of dropout.

Our findings on how relative age affects school achievement and dropout are of interest in themselves. Compared to two comparable recent studies, we find much larger effects on grade retention and dropout, and are able to clarify the extent of heterogeneity by race and sex. Our data set is exceptionally strong in several respects: we are able to track individuals in a cohort from birth through school and then crime up through age 19, and measure school outcomes from administrative data. ${ }^{17}$

${ }^{17}$ McCrary and Royer (2011) take education data from the Natality Detail File, which is to say birth certificates, where the education data are self-reported. Dobkin and Ferreira (2010) utilize the Decennial Census files, and there to the education data are self-reported. 


\section{References}

Anderson, D. Mark. 2012. "In School and Out of Trouble? The Minimum Dropout Age and Juvenile Crime.” Working Paper, Montana State University

Angrist, Joshua D., and Alan B. Krueger. 1991. "Does Compulsory School Attendance Affect Schooling and Earnings?” Quarterly Journal of Economics, 106(4): 979-1014.

Becker, Gary S. 1968. "Crime and Punishment: An Economic Approach." Journal of Political Economy, 76 (2): 169-217.

Bedard, Kelly, and Elizabeth Dhuey. 2006. “The Persistence of Early Maturity: International Evidence of Long-Run Age Effects.’’ Quarterly Journal of Economics 121(4):1437-72.

Black, Sandra, Paul Devereux, and Kjell Salvanes. 2011. "Too Young to Leave the Nest? The Effects of School Starting Age.” Review of Economics and Statistics, 93(2): 455-467.

Clay, Karen, Jeff Lingwall, Melvin Stephens, Jr. (2012) Do Schooling Laws Matter? Evidence from the Introduction of Compulsory Attendance Laws in the United States NBER Working Paper No 18477.

Datar, Ashlesha. 2006. “'Does Delaying Kindergarten Entrance Give Children a Head Start?” Economics of Education Review, 25(1):43-62.

Deming, David, and Susan Dynarski. 2008. "The Lengthening of Childhood." Journal of Economic Perspectives, 22(3): 71-92.

Dobkin, Carlos and Fernando Ferreira. 2010. "Do School Entry Laws Affect Educational Attainment and Labor Market Outcomes?” Economics of Education Review, 29(1): 40-54.

Elder, Todd E. and Darren H. Lubotsky. 2009. “Kindergarten Entrance Age and Children’s Achievement: Impacts of State Policies, Family Background, and Peers.” Journal of Human Resources 44(3): 641-683.

Fan, Jianqing and Irene Gijbels. 1992. "Variable Bandwidth and Local Linear Regression Smoothers.” Annals of Statistics 20:2008-2036.

Hahn, Jinyong, Petra Todd, and Wilbert Van der Klaauw. 2001. "Identification and Estimation of Treatment Effects with a Regression-Discontinuity Design.” Econometrica, 69: 201-209.

Harlow, Caroline W. 2003. "Education and Correctional Populations.” Bureau of Justice Statistics Special Report. Washington, DC.

Hjalmarsson, Randi. 2008. “Criminal Justice Involvement and High School Completion.” Journal of Urban Economics, 63(2):613-30. 
Hjalmarsson, Randi, Helena Holmlund, and Matthew J. Lindquis. 2012. "The Effect of Education on Criminal Convictions and Incarceration: Causal Evidence from Micro-data." Working Paper, Stockholm University.

Imbens, Guido and Karthik Kalyanaraman. 2012. "Optimal Bandwidth Choice for the Regression Discontinuity Estimator.” Review of Economic Studies, 79: 933-959.

Imbens, Guido and Thomas Lemieux. 2008. "Regression Discontinuity Designs: A Guide to Practice.” Journal of Econometrics, 142: 615-635.

Jacob, Bryan A. and Lars Lefgren. 2003. "Are Idle Hands the Devil’s Workshop? Incapacitation, Concentration, and Juvenile Crime.” American Economic Review, 93: 1560-1577.

Lee, David S., and Thomas Lemieux. 2010. "Regression Discontinuity Designs in Economics." Journal of Economic Literature, 48(2): 281-355.

Lleras-Muney, Adriana. 2005. "The Relationship between Education and Adult Mortality in the United States.” Review of Economic Studies, 72: 189-221.

Lochner, Lance. 2004. "Education, Work, and Crime: A Human Capital Approach." International Economic Review, 45(3): 811-43.

Lochner, Lance and Enrico Moretti. 2004. "The Effect of Education on Crime: Evidence from Prison Inmates, Arrests and Self-Reports.” American Economic Review, 94(1): 155-189.

Luallen, Jeremy. 2006. "Schools' out...forever: A Study of Juvenile Crime, At-risk Youths and Teacher Strikes.” Journal of Urban Economics, 59: 75-103.

Ludwig, Jens, and Douglas L. Miller. 2007. "Does Head Start Improve Children’s Life Chances? Evidence from a Regression Discontinuity Design.” Quarterly Journal of Economics, 122(1): 159-208.

Machin, Stephen, Olivier Marie and Suncica Vujic. 2011. "The Crime Reducing Effect of Education.” Economic Journal, 121:463-484.

McCrary, Justin and Heather Royer. 2011. "The Effect of Maternal Education on Fertility and Infant Health: Evidence from School Entry Policies Using Exact Date of Birth.” American Economic Review 101(1): 158-195.

McEwan, Patrick and Joseph Shapiro. 2008. "The Benefits of Delayed Primary School Enrollment: Discontinuity Estimates using Exact Birth Dates.” Journal of Human Resources, 43(1): 1-29. 
North Carolina State Board of Education. 1996. “End of Grade Tests, Technical Report \#1.” Raleigh, NC.

Oreopoulos, Philip. 2007. "Do Dropouts Drop Out Too Soon? Wealth, Health and Happiness from Compulsory Schooling.” Journal of Public Economics, 91: 2213-2229.

Pommerich, Mary, Kathleen Billeaud, Valerie Williams, and David Thissen. 1993. "User's Guide for the North Carolina End of Grade Tests.” L.L. Thurston Psychometric Laboratory, University of North Carolina at Chapel Hill.

Puhani, Patrick A. and Andrea M. Weber. 2005. "Does the Early Bird Catch the Worm? Instrumental Variable Estimates of Educational Effects of Age at School Entry in Germany." IZA Discussion Paper.

Raphael, Steven and Melissa Sills (2008) "Urban crime, race and the criminal justice system in the United States” In Companion to Urban Economics, edited by Daniel P. McMillen and Richard Arnott, 515-35, New York: Blackwell Publishing.

Thistlethwaite, Donald L. and Donald T. Campbell. 1960. "Regression-Discontinuity Analysis: An Alternative to the ex post facto Experiment," Journal of Educational Psychology, 51 (6): 309317. 
Table 1: Descriptive Statistics

\begin{tabular}{lcccc}
\hline \hline Cohort: & \multicolumn{2}{c}{$1987-1988$} & \multicolumn{2}{c}{$1991-1993$} \\
Samples born within X Days of Cutoff Date: & 120 Days & 60 Days & 120 Days & 60 Days \\
\hline Male & $49.0 \%$ & $49.3 \%$ & $48.6 \%$ & $48.7 \%$ \\
Black & $30.6 \%$ & $30.3 \%$ & $32.0 \%$ & $31.9 \%$ \\
Unwed mother & $26.0 \%$ & $25.8 \%$ & $33.2 \%$ & $33.0 \%$ \\
Born to Teenage Mother & $10.3 \%$ & $10.1 \%$ & $10.5 \%$ & $10.6 \%$ \\
Mother's Education < High School & $12.5 \%$ & $12.5 \%$ & $11.7 \%$ & $11.7 \%$ \\
Birth Weight < 2500 grams & $7.3 \%$ & $7.2 \%$ & $7.7 \%$ & $7.7 \%$ \\
Free/Reduced Price Lunch , Age 11 & & & $43.8 \%$ & $43.6 \%$ \\
Grade Level, Age 11 & 5.3 & 5.3 & 5.3 & 5.3 \\
Grade Level, Age 15 & 9.3 & 9.2 & 9.3 & 9.2 \\
Grade 6 Reading Percentile & 49.2 & 49.4 & 50.0 & 50.3 \\
Grade 7 Reading Percentile & 48.4 & 48.6 & 49.8 & 50.0 \\
Grade 8 Reading Percentile & 48.5 & 48.7 & 49.4 & 49.6 \\
Grade 6 Math Percentile & 50.1 & 50.3 & 50.8 & 51.0 \\
Grade 7 Math Percentile & 49.7 & 50.0 & 50.7 & 50.8 \\
Grade 8 Math Percentile & 49.5 & 49.6 & 51.4 & 51.5 \\
Grade Retention, Age 11-15 & $8.4 \%$ & $8.1 \%$ & $5.6 \%$ & $5.4 \%$ \\
School Enrollment, 3 Years after Grade 8 & $89.4 \%$ & $89.3 \%$ & & \\
School Enrollment, 4 Years after Grade 8 & $79.0 \%$ & $78.8 \%$ & & \\
Juvenile Delinquency Age 13-15 & \multicolumn{3}{c}{$9.0 \%$} & $8.8 \%$ \\
Criminal Conviction, Age 17-19 & $5.7 \%$ & $5.8 \%$ & & \\
\hline Obs. & 69572 & 35213 & 110244 & 55318 \\
\hline
\end{tabular}

Note: Sample is composed of students born around the school entry cutoff dates in 1987-1988 and 19911993. Each cohort is defined by students born between June 19 of the given year and February 14 of the following year (120 days before and after the cutoff date of October 17 (= Day 0), respectively). The sample is further restricted to students 1) who attended NC public schools between age 11 and 15, 2) whose NC birth certificate information is available. 
Table 2: Effect of School Entry Eligibility on Grade Level Configuration

\begin{tabular}{|c|c|c|c|c|}
\hline Outcome: Grade Level at & \multicolumn{2}{|c|}{ Age 11} & \multicolumn{2}{|c|}{ Age 15} \\
\hline \multicolumn{5}{|l|}{ (A) 1987-1988 Cohort } \\
\hline $\mathrm{D}$ & $\begin{array}{c}-0.578^{* * *} \\
(0.013)\end{array}$ & $\begin{array}{c}-0.579 * * * \\
(0.012)\end{array}$ & $\begin{array}{c}-0.520 * * * \\
(0.013)\end{array}$ & $\begin{array}{c}-0.521 * * * \\
(0.012)\end{array}$ \\
\hline R (x100) & $\begin{array}{c}-0.403 * * * \\
(0.042)\end{array}$ & $\begin{array}{c}-0.397 * * * \\
(0.039)\end{array}$ & $\begin{array}{c}-0.374 * * * \\
(0.041)\end{array}$ & $\begin{array}{c}-0.369 * * * \\
(0.037)\end{array}$ \\
\hline DR (x100) & $\begin{array}{c}0.303^{* * *} \\
(0.045)\end{array}$ & $\begin{array}{c}0.299 * * * \\
(0.042)\end{array}$ & $\begin{array}{c}0.289 * * * \\
(0.045)\end{array}$ & $\begin{array}{c}0.295^{* * *} \\
(0.042)\end{array}$ \\
\hline Male & & $\begin{array}{c}-0.122^{* * *} \\
(0.011)\end{array}$ & & $\begin{array}{c}-0.171^{* * *} \\
(0.013)\end{array}$ \\
\hline Black & & $\begin{array}{c}0.039 * * * \\
(0.009)\end{array}$ & & $\begin{array}{c}-0.009 \\
(0.009)\end{array}$ \\
\hline Unwed Mother & & $\begin{array}{c}-0.062^{* * *} \\
(0.006)\end{array}$ & & $\begin{array}{c}-0.103^{* * *} \\
(0.008)\end{array}$ \\
\hline Teenage Mother & & $\begin{array}{c}-0.051^{* * *} \\
(0.009)\end{array}$ & & $\begin{array}{c}-0.093 * * * \\
(0.011)\end{array}$ \\
\hline Mother's Ed. < HS & & $\begin{array}{c}-0.108 * * * \\
(0.008)\end{array}$ & & $\begin{array}{c}-0.195 * * * \\
(0.011)\end{array}$ \\
\hline Low Birthweight & & $\begin{array}{c}-0.076 * * * \\
(0.011)\end{array}$ & & $\begin{array}{c}-0.089 * * * \\
(0.013)\end{array}$ \\
\hline Constant & $\begin{array}{c}5.559 * * * \\
(0.012)\end{array}$ & $\begin{array}{c}5.651^{* * *} \\
(0.013)\end{array}$ & $\begin{array}{c}9.450 * * * \\
(0.012)\end{array}$ & $\begin{array}{c}9.607 * * * \\
(0.015)\end{array}$ \\
\hline R-squared & 0.408 & 0.430 & 0.291 & 0.339 \\
\hline Obs. & 34,560 & 34,560 & 34,560 & 34,560 \\
\hline \multicolumn{5}{|l|}{ (B) 1991-1993 Cohort } \\
\hline $\mathrm{D}$ & $\begin{array}{c}-0.567 * * * \\
(0.013)\end{array}$ & $\begin{array}{c}-0.567 * * * \\
(0.012)\end{array}$ & $\begin{array}{c}-0.511^{* * *} \\
(0.013)\end{array}$ & $\begin{array}{c}-0.510 * * * \\
(0.011)\end{array}$ \\
\hline $\mathrm{R}(\mathrm{x} 100)$ & $\begin{array}{c}-0.327 * * * \\
(0.038)\end{array}$ & $\begin{array}{c}-0.322 * * * \\
(0.034)\end{array}$ & $\begin{array}{c}-0.309 * * * \\
(0.038)\end{array}$ & $\begin{array}{c}-0.304 * * * \\
(0.033)\end{array}$ \\
\hline DR (x100) & $\begin{array}{c}0.221^{* * *} \\
(0.042)\end{array}$ & $\begin{array}{c}0.219 * * * \\
(0.039)\end{array}$ & $\begin{array}{c}0.197 * * * \\
(0.043)\end{array}$ & $\begin{array}{c}0.194 * * * \\
(0.038)\end{array}$ \\
\hline Male & & $\begin{array}{c}-0.124 * * * \\
(0.008)\end{array}$ & & $\begin{array}{c}-0.158 * * * \\
(0.010)\end{array}$ \\
\hline Black & & $\begin{array}{c}0.052 * * * \\
(0.007)\end{array}$ & & $\begin{array}{c}0.036 * * * \\
(0.007)\end{array}$ \\
\hline Unwed Mother & & $\begin{array}{c}-0.047 * * * \\
(0.007)\end{array}$ & & $\begin{array}{c}-0.068 * * * \\
(0.007)\end{array}$ \\
\hline Teenage Mother & & $\begin{array}{c}-0.054 * * * \\
(0.009)\end{array}$ & & $\begin{array}{c}-0.072 * * * \\
(0.010)\end{array}$ \\
\hline Mother's Ed. < HS & & $\begin{array}{c}-0.133^{* * *} \\
(0.008)\end{array}$ & & $\begin{array}{c}-0.171^{* * *} \\
(0.009)\end{array}$ \\
\hline
\end{tabular}




\begin{tabular}{lcccc} 
Low Birthweight & & $-0.084^{* * *}$ & & $-0.084 * * *$ \\
& & $(0.011)$ & & $(0.011)$ \\
Free/Reduced Lunch & & $-0.113^{* * *}$ & & $-0.148^{* * *}$ \\
& & $(0.006)$ & & $(0.006)$ \\
Constant & $5.522 * * *$ & $5.652 * * *$ & $9.444 * * *$ & $9.619 * * *$ \\
& $(0.011)$ & $(0.011)$ & $(0.011)$ & $(0.013)$ \\
R-squared & 0.342 & 0.379 & 0.274 & 0.337 \\
Obs. & 54,416 & 54,416 & 54,416 & 54,416 \\
\hline
\end{tabular}

Note: First and third columns correspond to a baseline specification in which the outcome measure, grade level at age 11 or 15, is regressed on birthdays (R), post-cutoff indicator (D) and its interaction term (DR). Second and fourth columns correspond to an extended specification in which additional individual covariates are included. Panel (A) reports estimates obtained from 1987 and 1988 cohorts, and Panel (B) estimates from the 1991-1993 cohorts. Coefficients and standard errors on R and DR are multiplied by 100. Robust standard errors clustered at the birthday level are in parentheses. $* * * \mathrm{p}<0.01, * * \mathrm{p}<0.05$, * $\mathrm{p}<0.1$. All specifications include cohort-fixed effects. 
Table 3: Effect of School Entry Eligibility on EOG Reading Achievement

\begin{tabular}{lcccccc}
\hline \hline Cohort: & \multicolumn{3}{c}{$1987-1988$} & \multicolumn{3}{c}{$1991-1993$} \\
Outcome: & \multicolumn{2}{c}{ EOG Reading Percentile } & \multicolumn{2}{c}{ EOG Reading Percentile } \\
& Grade 6 & Grade 7 & Grade 8 & Grade 6 & Grade 7 & Grade 8 \\
\hline D & $6.250^{* * *}$ & $6.001^{* * *}$ & $4.708^{* * *}$ & $5.487^{* * *}$ & $4.700^{* * *}$ & $4.178^{* * *}$ \\
& $(0.615)$ & $(0.592)$ & $(0.512)$ & $(0.450)$ & $(0.503)$ & $(0.580)$ \\
R & -0.021 & -0.010 & -0.005 & $0.017^{*}$ & 0.017 & 0.016 \\
& $(0.014)$ & $(0.014)$ & $(0.012)$ & $(0.010)$ & $(0.011)$ & $(0.010)$ \\
DR & 0.017 & -0.007 & 0.001 & $-0.032^{* *}$ & $-0.033^{* *}$ & -0.024 \\
& $(0.020)$ & $(0.019)$ & $(0.017)$ & $(0.014)$ & $(0.016)$ & $(0.018)$ \\
Male & $-4.504^{* * *}$ & $-4.066^{* * *}$ & $-3.903^{* * *}$ & $-4.837^{* * *}$ & $-4.760^{* * *}$ & $-3.653^{* * *}$ \\
& $(0.323)$ & $(0.285)$ & $(0.292)$ & $(0.237)$ & $(0.257)$ & $(0.231)$ \\
Black & $-17.244^{* * *}$ & $-17.779^{* * *}$ & $-18.310^{* * *}$ & $-13.507^{* * *}$ & $-12.582^{* * *}$ & $-13.047 * * *$ \\
& $(0.418)$ & $(0.393)$ & $(0.433)$ & $(0.347)$ & $(0.339)$ & $(0.314)$ \\
Unwed Mother & $-7.924^{* * *}$ & $-7.503^{* * *}$ & $-7.485^{* * *}$ & $-4.969^{* * *}$ & $-5.440^{* * *}$ & $-5.599^{* * *}$ \\
& $(0.475)$ & $(0.430)$ & $(0.501)$ & $(0.325)$ & $(0.316)$ & $(0.317)$ \\
Teenage Mother & $-7.824^{* * *}$ & $-8.103^{* * *}$ & $-8.082^{* * *}$ & $-5.010^{* * *}$ & $-5.043^{* * *}$ & $-5.050^{* * *}$ \\
& $(0.537)$ & $(0.489)$ & $(0.536)$ & $(0.430)$ & $(0.435)$ & $(0.420)$ \\
Mother's Ed. $<$ HS & $-15.952^{* * *}$ & $-16.116^{* * *}$ & $-15.858^{* * *}$ & $-10.540^{* * *}$ & $-11.181^{* * *}$ & $-10.580^{* * *}$ \\
& $(0.504)$ & $(0.529)$ & $(0.497)$ & $(0.345)$ & $(0.345)$ & $(0.327)$ \\
Low Birthweight & $-2.786^{* * *}$ & $-2.183^{* * *}$ & $-2.525^{* * *}$ & $-1.366^{* * *}$ & $-1.058^{* *}$ & -0.633 \\
& $(0.681)$ & $(0.707)$ & $(0.686)$ & $(0.495)$ & $(0.409)$ & $(0.414)$ \\
Free/Reduced Lunch & & & & $-12.653^{* * *}$ & $-12.313^{* * *}$ & $-12.845^{* * *}$ \\
Constant & & & & $(0.208)$ & $(0.261)$ & $(0.268)$ \\
& $58.981^{* * *}$ & $58.461^{* * *}$ & $58.723^{* * *}$ & $63.071^{* * *}$ & $63.022^{* * *}$ & $62.257^{* * *}$ \\
Obs. & $(0.471)$ & $(0.498)$ & $(0.431)$ & $(0.444)$ & $(0.420)$ & $(0.442)$ \\
& 0.198 & 0.199 & 0.204 & 0.245 & 0.233 & 0.240 \\
\hline
\end{tabular}

Note: Each column corresponds to an extended specification in which the outcome measure, EOG reading percentiles, are regressed on birthdays (R), post-cutoff indicator (D) and its interaction term (DR), as well as other individual covariates. First three columns correspond to estimates obtained from 1987 and 1988 cohorts, and the next three correspond to 1991, 1992 and 1993 cohorts. Robust standard errors clustered at the birthday level are in parentheses. $* * * \mathrm{p}<0.01, * * \mathrm{p}<0.05, * \mathrm{p}<0.1$. All specifications include cohort-fixed effects. 
Table 4: Effect of School Entry Eligibility on Grade Retention and High School Attainment

\begin{tabular}{lcccc}
\hline \hline Cohort: & \multicolumn{3}{c}{$1987-1988$} & $1991-1993$ \\
Outcome: & Grade Retention & Enrollment & Enrollment & Grade Retention \\
& Age 11-15 & Year 11 & Year 12 & Age 11-15 \\
\hline $\mathrm{D}$ & $-5.712^{* * *}$ & $-2.386^{* * *}$ & $-4.448^{* * *}$ & $-5.588^{* * *}$ \\
& $(0.482)$ & $(0.781)$ & $(0.773)$ & $(0.400)$ \\
$\mathrm{R}$ & $-0.026^{*}$ & 0.011 & $-0.030^{*}$ & -0.018 \\
& $(0.014)$ & $(0.019)$ & $(0.018)$ & $(0.012)$ \\
DR & 0.004 & -0.003 & 0.014 & $0.022^{*}$ \\
& $(0.017)$ & $(0.026)$ & $(0.026)$ & $(0.013)$ \\
Male & $4.800^{* * *}$ & $-2.336^{* * *}$ & $-3.328^{* * *}$ & $3.519^{* * *}$ \\
& $(0.388)$ & $(0.367)$ & $(0.494)$ & $(0.296)$ \\
Black & $4.753^{* * *}$ & $4.062^{* * *}$ & $7.056^{* * *}$ & $1.609^{* * *}$ \\
& $(0.495)$ & $(0.547)$ & $(0.706)$ & $(0.317)$ \\
Unwed Mother & $4.134^{* * *}$ & $-5.572^{* * *}$ & $-8.127 * * *$ & $2.084^{* * *}$ \\
& $(0.571)$ & $(0.639)$ & $(0.795)$ & $(0.367)$ \\
Teenage Mother & $4.181^{* * *}$ & $-8.098^{* * *}$ & $-11.145^{* * *}$ & $1.916^{* * *}$ \\
& $(0.630)$ & $(0.986)$ & $(1.082)$ & $(0.482)$ \\
Mother's Ed. $<$ HS & $8.477^{* * *}$ & $-14.366^{* * *}$ & $-17.471^{* * *}$ & $4.080^{* * *}$ \\
& $(0.735)$ & $(0.761)$ & $(0.792)$ & $(0.460)$ \\
Low Birthweight & $1.217^{* *}$ & $-1.322^{*}$ & 0.211 & 0.013 \\
& $(0.613)$ & $(0.733)$ & $(0.935)$ & $(0.445)$ \\
Free/Reduced Lunch & & & & $3.578^{* * *}$ \\
Constant & & & & $(0.325)$ \\
R-squared & $(0.546)$ & $(0.643)$ & $(0.793)$ & $(0.477)$ \\
\hline Obs. & 0.053 & 0.039 & 0.045 & 0.048 \\
\hline
\end{tabular}

Note: Each column corresponds to an extended specification in which outcome measures are regressed on birthdays (R), post-cutoff indicator (D) and its interaction term (DR), as well as other individual covariates. First three columns correspond to estimates obtained from 1987 and 1988 cohorts, and the last column corresponds to 1991, 1992 and 1993 cohorts. Robust standard errors clustered at the birthday level are in parentheses. ${ }^{* * *} \mathrm{p}<0.01,{ }^{* *} \mathrm{p}<0.05,{ }^{*} \mathrm{p}<0.1$. All specifications include cohort-fixed effects. 
Table 5: Effect of School Entry Eligibility on Juvenile Delinquency

\begin{tabular}{|c|c|c|c|c|}
\hline \multirow{2}{*}{$\begin{array}{l}\text { Cohort: } \\
\text { Outcome: }\end{array}$} & \multicolumn{4}{|c|}{ 1991-1993 } \\
\hline & Age 13-15 & Age 13 & Age 14 & Age 15 \\
\hline $\mathrm{D}$ & $\begin{array}{c}-2.803^{* * *} \\
(0.571)\end{array}$ & $\begin{array}{c}-0.443 \\
(0.316)\end{array}$ & $\begin{array}{c}-1.474 * * * \\
(0.394)\end{array}$ & $\begin{array}{c}-1.774 * * * \\
(0.394)\end{array}$ \\
\hline $\mathrm{R}$ & $\begin{array}{l}0.028^{*} \\
(0.015)\end{array}$ & $\begin{array}{c}0.006 \\
(0.009)\end{array}$ & $\begin{array}{c}0.020^{* *} \\
(0.010)\end{array}$ & $\begin{array}{c}0.016 \\
(0.010)\end{array}$ \\
\hline $\mathrm{DR}$ & $\begin{array}{c}-0.001 \\
(0.019)\end{array}$ & $\begin{array}{c}-0.001 \\
(0.010)\end{array}$ & $\begin{array}{c}-0.006 \\
(0.013)\end{array}$ & $\begin{array}{c}0.006 \\
(0.013)\end{array}$ \\
\hline Male & $\begin{array}{c}4.581 * * * \\
(0.304)\end{array}$ & $\begin{array}{c}1.454 * * * \\
(0.152)\end{array}$ & $\begin{array}{c}2.297 * * * \\
(0.163)\end{array}$ & $\begin{array}{c}2.650 * * * \\
(0.226)\end{array}$ \\
\hline Black & $\begin{array}{c}1.002 * * * \\
(0.353)\end{array}$ & $\begin{array}{l}0.422^{*} \\
(0.229)\end{array}$ & $\begin{array}{c}0.194 \\
(0.229)\end{array}$ & $\begin{array}{c}0.907 * * * \\
(0.273)\end{array}$ \\
\hline Unwed Mother & $\begin{array}{c}3.994 * * * \\
(0.453)\end{array}$ & $\begin{array}{c}1.399 * * * \\
(0.239)\end{array}$ & $\begin{array}{c}1.916^{* * * *} \\
(0.301)\end{array}$ & $\begin{array}{c}2.485^{* * *} \\
(0.314)\end{array}$ \\
\hline Teenage Mother & $\begin{array}{c}3.686 * * * \\
(0.732)\end{array}$ & $\begin{array}{c}0.855^{* *} \\
(0.349)\end{array}$ & $\begin{array}{c}1.376^{* * * *} \\
(0.421)\end{array}$ & $\begin{array}{c}2.393 * * * \\
(0.519)\end{array}$ \\
\hline Mother's Ed. < HS & $\begin{array}{c}6.217 * * * \\
(0.592)\end{array}$ & $\begin{array}{c}2.167 * * * \\
(0.345)\end{array}$ & $\begin{array}{c}3.407 * * * \\
(0.412)\end{array}$ & $\begin{array}{c}2.810 * * * \\
(0.428)\end{array}$ \\
\hline Low Birthweight & $\begin{array}{c}-1.191^{* *} \\
(0.568)\end{array}$ & $\begin{array}{l}-0.189 \\
(0.355)\end{array}$ & $\begin{array}{c}-0.354 \\
(0.369)\end{array}$ & $\begin{array}{c}-1.062^{* * *} \\
(0.390)\end{array}$ \\
\hline Free/Reduced Lunch & $\begin{array}{c}6.641 * * * \\
(0.379)\end{array}$ & $\begin{array}{c}1.807 * * * \\
(0.171)\end{array}$ & $\begin{array}{c}3.073 * * * \\
(0.234)\end{array}$ & $\begin{array}{c}3.671^{* * *} \\
(0.292)\end{array}$ \\
\hline Constant & $\begin{array}{c}2.855^{* * * *} \\
(0.488)\end{array}$ & $\begin{array}{c}0.245 \\
(0.266)\end{array}$ & $\begin{array}{c}1.052 * * * \\
(0.307)\end{array}$ & $\begin{array}{c}1.577 * * * \\
(0.342)\end{array}$ \\
\hline R-squared & 0.049 & 0.016 & 0.024 & 0.028 \\
\hline Obs. & 54,416 & 54,416 & 54,416 & 54,416 \\
\hline
\end{tabular}

Note: Each column corresponds to an extended specification, in which juvenile delinquency outcome for a given age level is regressed on birthdays (R), post-cutoff indicator (D) and its interaction term (DR), as well as other individual covariates. Robust standard errors clustered at the birthday level are in parentheses. ${ }^{* * *} \mathrm{p}<0.01,{ }^{* *} \mathrm{p}<0.05,{ }^{*} \mathrm{p}<0.1$. All specifications include cohort-fixed effects. 
Table 6: Effect of School Entry Eligibility on Adult Criminal Conviction

\begin{tabular}{|c|c|c|c|c|}
\hline \multirow{2}{*}{$\begin{array}{l}\text { Cohort: } \\
\text { Outcome: Crime Committed at }\end{array}$} & \multicolumn{4}{|c|}{ 1987-1988 } \\
\hline & Age $17-19$ & Age 17 & Age 18 & Age 19 \\
\hline \multirow[t]{2}{*}{$\mathrm{D}$} & $0.851^{*}$ & -0.033 & -0.174 & $0.849 * *$ \\
\hline & $(0.469)$ & $(0.288)$ & $(0.313)$ & $(0.339)$ \\
\hline \multirow[t]{2}{*}{$\mathrm{R}$} & -0.016 & -0.000 & 0.001 & $-0.017^{* *}$ \\
\hline & $(0.010)$ & $(0.006)$ & $(0.009)$ & $(0.008)$ \\
\hline \multirow[t]{2}{*}{ DR } & 0.013 & 0.006 & 0.010 & 0.010 \\
\hline & $(0.015)$ & $(0.010)$ & $(0.011)$ & $(0.012)$ \\
\hline \multirow[t]{2}{*}{ Male } & $6.634 * * *$ & $2.566 * * *$ & $3.394 * * *$ & $3.172 * * *$ \\
\hline & $(0.291)$ & $(0.177)$ & $(0.210)$ & $(0.192)$ \\
\hline \multirow[t]{2}{*}{ Black } & $2.596 * * *$ & $0.973 * * *$ & $1.334 * * *$ & $1.036 * * *$ \\
\hline & $(0.397)$ & $(0.257)$ & $(0.270)$ & $(0.270)$ \\
\hline \multirow[t]{2}{*}{ Unwed Mother } & $4.303^{* * *}$ & $1.789 * * *$ & $2.014^{* * *}$ & $1.875^{* * *}$ \\
\hline & $(0.442)$ & $(0.292)$ & $(0.287)$ & $(0.292)$ \\
\hline \multirow[t]{2}{*}{ Teenage Mother } & $2.906 * * *$ & $1.309 * * *$ & $1.512 * * *$ & $1.134 * * *$ \\
\hline & $(0.561)$ & $(0.406)$ & $(0.423)$ & $(0.408)$ \\
\hline \multirow[t]{2}{*}{ Mother's Ed. < HS } & $3.955 * * *$ & $1.281^{* * *}$ & $2.308^{* * *}$ & $1.454 * * *$ \\
\hline & $(0.497)$ & $(0.273)$ & $(0.392)$ & $(0.289)$ \\
\hline \multirow[t]{2}{*}{ Low Birthweight } & -0.508 & -0.217 & -0.500 & -0.266 \\
\hline & $(0.586)$ & $(0.318)$ & $(0.353)$ & $(0.406)$ \\
\hline \multirow[t]{2}{*}{ Free/Reduced Lunch } & $-0.865 * *$ & -0.312 & $-0.584 * *$ & $-0.526^{*}$ \\
\hline & $(0.393)$ & $(0.214)$ & $(0.290)$ & $(0.281)$ \\
\hline Constant & 0.039 & 0.017 & 0.022 & 0.016 \\
\hline Obs. & 34,560 & 34,560 & 34,560 & 34,560 \\
\hline
\end{tabular}

Note: Each column corresponds to an extended specification, in which adult crime outcome for a given age level is regressed on birthdays (R), post-cutoff indicator (D) and its interaction term (DR), as well as other individual covariates. Robust standard errors clustered at the birthday level are in parentheses. *** $\mathrm{p}<0.01,{ }^{* *} \mathrm{p}<0.05,{ }^{*} \mathrm{p}<0.1$. All specifications include cohort-fixed effects. 
Table 7: School Enrollment and Crime

\begin{tabular}{lcccc}
\hline \hline & Aggregate & Crime at Age 17 & Crime at Age 18 & Crime at Age 19 \\
\hline Enrollment, Age 16 & $94.6 \%$ & $81.8 \%$ & $84.5 \%$ & $84.7 \%$ \\
Enrollment, Age 17 & $88.6 \%$ & $67.2 \%$ & $69.4 \%$ & $70.4 \%$ \\
Enrollment, Age 18 or Grade 12 & $78.9 \%$ & $40.3 \%$ & $50.2 \%$ & $51.7 \%$ \\
\hline Obs. & 35,213 & 714 & 914 & 952 \\
\hline
\end{tabular}

Note: First column corresponds to our main sample who were born within 60 days of the school entry cutoff date in 1987 and 1988. The next three columns correspond to the individuals who committed felony offenses in ages 17, 18 and 19. Each entry represents the rate of enrollment for a given age/grade level. 
Table 8: Effect of School Entry Eligibility, by Race and Sex

\begin{tabular}{|c|c|c|c|c|}
\hline & White Male & White Female & Black Male & Black Female \\
\hline \multicolumn{5}{|l|}{ (A) 1987-1988 Cohort } \\
\hline \multirow[t]{3}{*}{ Grade Retention, Age 11-15 } & $-5.527 * * *$ & $-3.090 * * *$ & $-11.574 * * *$ & $-6.701 * * *$ \\
\hline & $(1.117)$ & $(0.732)$ & $(1.927)$ & $(1.710)$ \\
\hline & {$[7.776]$} & [4.191] & {$[16.835]$} & [9.249] \\
\hline \multirow[t]{3}{*}{ Grade Level, Age 15} & $-0.330 * * *$ & $-0.634 * * *$ & $-0.534 * * *$ & $-0.664 * * *$ \\
\hline & $(0.021)$ & $(0.020)$ & $(0.028)$ & $(0.031)$ \\
\hline & [9.183] & [9.342] & [9.088] & {$[9.256]$} \\
\hline \multirow[t]{3}{*}{ On-time Progress, Age 15} & $55.206 * * *$ & $27.339 * * *$ & $29.887 * * *$ & $18.149 * * *$ \\
\hline & $(91.791)$ & $(1.807)$ & $(1.954)$ & $(2.421)$ \\
\hline & [68.207] & [82.179] & [62.192] & {$[75.100]$} \\
\hline \multirow[t]{3}{*}{ School Enrollment, Year 12} & -1.349 & $-7.732 * * *$ & -2.286 & $-6.451 * * *$ \\
\hline & $(1.315)$ & $(1.213)$ & $(2.653)$ & $(1.883)$ \\
\hline & {$[77.227]$} & [79.313] & {$[76.766]$} & {$[83.261]$} \\
\hline \multirow[t]{3}{*}{ Crime, Age 17-19 } & 0.741 & 0.133 & 3.052 & 0.817 \\
\hline & $(0.860)$ & $(0.533)$ & $(2.142)$ & $(1.270)$ \\
\hline & [6.633] & [1.953] & [14.675] & [4.117] \\
\hline \multirow[t]{3}{*}{ Crime, Age 17} & -0.247 & -0.145 & 1.099 & -0.321 \\
\hline & $(0.583)$ & $(0.240)$ & $(1.357)$ & $(0.711)$ \\
\hline & [2.353] & [0.585] & {$[5.571]$} & [1.269] \\
\hline \multirow[t]{3}{*}{ Crime, Age 18} & -0.182 & 0.231 & -0.941 & 0.461 \\
\hline & $(0.599)$ & $(0.324)$ & (1.565) & $(0.784)$ \\
\hline & [2.933] & [0.714] & {$[7.226]$} & [1.578] \\
\hline \multirow[t]{3}{*}{ Crime, Age 19} & 0.846 & 0.147 & 1.651 & $1.271 * *$ \\
\hline & $(0.589)$ & $(0.368)$ & $(1.386)$ & $(0.616)$ \\
\hline & [3.206] & [0.912] & [6.803] & [1.705] \\
\hline Obs. & 11,729 & 11,621 & 4,954 & 5,514 \\
\hline \multicolumn{5}{|l|}{ (B) 1991-1993 Cohort } \\
\hline \multirow[t]{3}{*}{ Grade Retention, Age 11-15 } & $-5.520 * * *$ & $-2.995 * * *$ & $-11.071^{* * *}$ & $-6.429 * * *$ \\
\hline & $(0.696)$ & $(0.464)$ & $(1.254)$ & $(1.304)$ \\
\hline & {$[5.301]$} & [2.699] & [11.362] & {$[5.464]$} \\
\hline \multirow[t]{3}{*}{ Grade Level, Age 15} & $-0.373^{* * *}$ & $-0.606 * * *$ & $-0.509 * * *$ & $-0.583^{* * *}$ \\
\hline & $(0.018)$ & $(0.013)$ & $(0.029)$ & $(0.022)$ \\
\hline & [9.179] & [9.329] & {$[9.082]$} & {$[9.242]$} \\
\hline \multirow[t]{3}{*}{ On-time Progress, Age 15} & $51.747 * * *$ & $29.262 * * *$ & $31.807 * * *$ & $20.791 * * *$ \\
\hline & $(1.290)$ & $(1.202)$ & $(2.214)$ & $(1.784)$ \\
\hline & [67.384] & {$[80.156]$} & {$[59.731]$} & [72.109] \\
\hline \multirow[t]{3}{*}{ Juvenile Offense, Age 13-15 } & $-3.018 * * *$ & $-1.913^{* * *}$ & $-4.805^{* *}$ & -2.027 \\
\hline & $(0.690)$ & $(0.717)$ & $(2.029)$ & $(1.616)$ \\
\hline & [8.563] & [4.911] & {$[16.467]$} & [10.009] \\
\hline Juvenile Offense, Age 13 & $-1.019 * * *$ & -0.344 & -0.574 & 0.209 \\
\hline
\end{tabular}




\begin{tabular}{lcccc} 
& $(0.369)$ & $(0.324)$ & $(0.975)$ & $(0.816)$ \\
& {$[2.101]$} & {$[1.137]$} & {$[4.923]$} & {$[2.628]$} \\
Juvenile Offense, Age 14 & $-1.064^{* *}$ & $-1.097^{* *}$ & $-2.643^{* *}$ & $-1.322^{*}$ \\
& $(0.481)$ & $(0.430)$ & $(1.300)$ & $(0.723)$ \\
& {$[3.804]$} & {$[2.042]$} & {$[7.360]$} & {$[4.000]$} \\
Juvenile Offense, Age 15 & $-1.906^{* * *}$ & $-1.276^{* * *}$ & $-3.076^{*}$ & -1.212 \\
& $(0.604)$ & $(0.473)$ & $(1.560)$ & $(1.248)$ \\
& {$[4.635]$} & {$[2.687]$} & {$[9.895]$} & {$[5.618]$} \\
\hline Obs. & 17562 & 18121 & 8247 & 9132 \\
\hline
\end{tabular}

Note: Each entry refers to the RD estimate obtained for the given outcome (rows) and subgroup (column). $*_{* *} \mathrm{p}<0.01,{ }^{* *} \mathrm{p}<0.05, * \mathrm{p}<0.1$. Robust standard errors clustered at the birthday level are in parentheses. Sample means are reported in square bracket. All regression specifications include birthdays (R), postcutoff indicator (D), interaction term (DR), other individual covariates and cohort-fixed effects. 
Table 9: Effect of School Entry Eligibility, by Demographic Characteristics

\begin{tabular}{|c|c|c|c|}
\hline & Unwed Mother & Mother's Ed. < HS & Free/Red. Lunch \\
\hline \multicolumn{4}{|l|}{ (A) 1987-1988 Cohort } \\
\hline \multirow[t]{3}{*}{ Grade Retention, Age 11-15 } & $-9.368 * * *$ & $-11.818 * * *$ & \\
\hline & $(1.316)$ & $(2.086)$ & \\
\hline & [13.956] & {$[15.181]$} & \\
\hline \multirow[t]{3}{*}{ Grade Level, Age 15} & $-0.546 * * *$ & $-0.412 * * *$ & \\
\hline & $(0.022)$ & $(0.031)$ & \\
\hline & [9.118] & [9.058] & \\
\hline \multirow[t]{3}{*}{ On-time Progress, Age 15} & $30.107 * * *$ & $41.871 * * *$ & \\
\hline & $(1.679)$ & $(3.278)$ & \\
\hline & [64.628] & {$[60.401]$} & \\
\hline \multirow[t]{3}{*}{ School Enrollment, Year 12} & $-5.133 * *$ & $-5.944 * *$ & \\
\hline & $(2.094)$ & $(2.338)$ & \\
\hline & {$[72.603]$} & [63.810] & \\
\hline \multirow[t]{3}{*}{ Crime, Age 17-19 } & $3.002 * * *$ & $3.267 * *$ & \\
\hline & $(1.095)$ & $(1.382)$ & \\
\hline & [10.529] & [10.123] & \\
\hline \multirow[t]{3}{*}{ Crime, Age 17} & 0.753 & 0.854 & \\
\hline & $(0.690)$ & $(0.811)$ & \\
\hline & [4.043] & [3.156] & \\
\hline \multirow[t]{3}{*}{ Crime, Age 18} & 0.089 & 0.46 & \\
\hline & $(0.752)$ & $(1.265)$ & \\
\hline & [4.839] & {$[4.515]$} & \\
\hline \multirow[t]{3}{*}{ Crime, Age 19} & $2.129 * * *$ & $2.500 * * *$ & \\
\hline & $(0.750)$ & $(0.901)$ & \\
\hline & {$[4.760]$} & [3.985] & \\
\hline Obs. & 8928 & 4341 & \\
\hline \multicolumn{4}{|l|}{ (B) 1991-1993 Cohort } \\
\hline \multirow[t]{3}{*}{ Grade Retention, Age 11-15 } & $-9.049 * * *$ & $-9.748 * * *$ & $-8.621 * * *$ \\
\hline & $(1.039)$ & $(1.516)$ & $(0.757)$ \\
\hline & [8.774] & [9.998] & [8.665] \\
\hline \multirow[t]{3}{*}{ Grade Level, Age 15} & $-0.521 * * *$ & $-0.437 * * *$ & $-0.507 * * *$ \\
\hline & $(0.016)$ & $(0.022)$ & $(0.014)$ \\
\hline & [9.123] & [9.029] & [9.108] \\
\hline \multirow[t]{3}{*}{ On-time Progress, Age 15} & $32.440 * * *$ & $41.894 * * *$ & $34.833^{* * *}$ \\
\hline & $(1.023)$ & $(1.855)$ & $(1.237)$ \\
\hline & {$[63.716]$} & {$[56.826]$} & {$[62.728]$} \\
\hline \multirow[t]{3}{*}{ Juvenile Offense, Age 13-15 } & $-3.728 * *$ & $-4.979 * *$ & $-3.986 * * *$ \\
\hline & $(1.710)$ & $(2.076)$ & $(1.200)$ \\
\hline & [14.530] & [16.234] & {$[14.400]$} \\
\hline \multirow[t]{2}{*}{ Juvenile Offense, Age 13} & -0.927 & -0.406 & -0.573 \\
\hline & & 41 & \\
\hline
\end{tabular}




\begin{tabular}{lccc} 
& $(0.877)$ & $(1.136)$ & $(0.652)$ \\
Juvenile Offense, Age 14 & {$[4.067]$} & {$[4.834]$} & {$[3.993]$} \\
& $-2.271^{* *}$ & $-3.882^{* * *}$ & $-2.088^{* * *}$ \\
& $(0.987)$ & $(1.363)$ & $(0.772)$ \\
Juvenile Offense, Age 15 & {$[6.396]$} & {$[7.558]$} & {$[6.355]$} \\
& $-2.009^{*}$ & $-3.215^{* *}$ & $-2.458^{* * *}$ \\
& $(1.043)$ & $(1.351)$ & $(0.873)$ \\
\hline Obs. & {$[8.490]$} & {$[8.629]$} & {$[8.189]$} \\
\hline
\end{tabular}

Note: Each entry refers to the RD estimate obtained for the given outcome (rows) and subgroup (column). $*_{* *} \mathrm{p}<0.01,{ }^{* *} \mathrm{p}<0.05, * \mathrm{p}<0.1$. Robust standard errors clustered at the birthday level are in parentheses. Sample means are reported in square bracket. All regression specifications include birthdays (R), postcutoff indicator (D), interaction term (DR), other individual covariates and cohort-fixed effects. 
Table 10: Continuity of Covariates at the Cutoff

\begin{tabular}{lccccccc}
\hline \hline & Male & Black & $\begin{array}{c}\text { Unwed } \\
\text { Mother }\end{array}$ & $\begin{array}{c}\text { Teenage } \\
\text { Mother }\end{array}$ & $\begin{array}{c}\text { Mother's } \\
\text { Ed. }<\text { HS }\end{array}$ & $\begin{array}{c}\text { Low } \\
\text { Birthweight }\end{array}$ & $\begin{array}{l}\text { Free/Red. } \\
\text { Lunch }\end{array}$ \\
\hline (A) 1987-1988 Cohorts & & & & & & \\
D & -0.029 & 0.701 & 0.014 & 0.013 & 0.119 & -0.846 & \\
& $(1.259)$ & $(0.985)$ & $(1.146)$ & $(0.768)$ & $(0.749)$ & $(0.694)$ & \\
Constant & $49.553^{* * *}$ & $28.232^{* * *}$ & $24.468^{* * *}$ & $9.876^{* * *}$ & $12.472^{* * *}$ & $8.197^{* * *}$ & \\
& $(0.989)$ & $(0.585)$ & $(0.632)$ & $(0.490)$ & $(0.639)$ & $(0.538)$ & \\
R-squared & 0.000 & 0.001 & 0.001 & 0.000 & 0.000 & 0.000 & \\
\hline Obs. & 34,560 & 34,560 & 34,560 & 34,560 & 34,560 & 34,560 & \\
\hline (B) 1991-1993 Cohorts & & & & & & \\
D & -1.257 & 0.819 & 0.716 & 0.661 & 0.358 & -0.280 & 0.734 \\
& $(1.027)$ & $(1.036)$ & $(1.068)$ & $(0.637)$ & $(0.763)$ & $(0.413)$ & $(1.084)$ \\
Constant & $49.058^{* * *}$ & $31.213^{* * *}$ & $32.240^{* * *}$ & $10.303^{* * *}$ & $11.833^{* * *}$ & $7.642^{* * *}$ & $43.634 * * *$ \\
\multicolumn{1}{l}{ R-squared } & $(0.837)$ & $(0.859)$ & $(0.815)$ & $(0.502)$ & $(0.637)$ & $(0.306)$ & $(0.930)$ \\
\hline Obs. & 0.000 & 0.000 & 0.000 & 0.000 & 0.000 & 0.000 & 0.000 \\
\hline
\end{tabular}

Note: Presented in each column is the discontinuity estimate of the given variable at the cutoff date, as well as the constant term and R-squared. Results from the 1987-1988 cohorts (Panel A) and 1991-1993 cohorts (Panel B) are reported separately. ${ }^{* * *} \mathrm{p}<0.01,{ }^{* *} \mathrm{p}<0.05,{ }^{*} \mathrm{p}<0.1$. Robust standard errors clustered at the birthday level are in parentheses. All regression specifications include birthdays (R), post-cutoff indicator (D), their interaction term (DR) and cohort-fixed effects. 
Table 11: Robustness to Bandwidth Choices

\begin{tabular}{|c|c|c|c|}
\hline Bandwidth = & 10 & 30 & 60 \\
\hline \multicolumn{4}{|l|}{ (A) 1987-1988 Cohorts } \\
\hline Grade 6 Reading Percentile & $\begin{array}{c}6.128 * * * \\
(1.500)\end{array}$ & $\begin{array}{c}5.971 * * * \\
(0.772)\end{array}$ & $\begin{array}{c}6.250 * * * \\
(0.615)\end{array}$ \\
\hline Grade 7 Reading Percentile & $\begin{array}{c}7.524^{* * *} \\
(1.609)\end{array}$ & $\begin{array}{c}5.915^{* * *} \\
(0.846)\end{array}$ & $\begin{array}{c}6.001^{* * *} \\
(0.592)\end{array}$ \\
\hline Grade 8 Reading Percentile & $\begin{array}{c}4.806^{* * *} \\
(1.412)\end{array}$ & $\begin{array}{c}4.438 * * * \\
(0.668)\end{array}$ & $\begin{array}{c}4.708^{* * *} \\
(0.512)\end{array}$ \\
\hline Grade Retention, Age 11-15 & $\begin{array}{c}-4.066^{* * *} \\
(0.626)\end{array}$ & $\begin{array}{c}-4.575^{* * *} \\
(0.567)\end{array}$ & $\begin{array}{c}-5.712 * * * \\
(0.482)\end{array}$ \\
\hline School Enrollment, Year 12 & $\begin{array}{c}-1.824^{*} \\
(0.984)\end{array}$ & $\begin{array}{c}-3.521^{* * *} \\
(0.961)\end{array}$ & $\begin{array}{c}-4.448 * * * \\
(0.773)\end{array}$ \\
\hline Crime, Age 17-19 & $\begin{array}{c}1.221 \\
(0.787)\end{array}$ & $\begin{array}{c}0.853 \\
(0.526)\end{array}$ & $\begin{array}{l}0.851^{*} \\
(0.469)\end{array}$ \\
\hline Crime, Age 17 & $\begin{array}{l}-0.218 \\
(0.513)\end{array}$ & $\begin{array}{l}-0.420 \\
(0.344)\end{array}$ & $\begin{array}{l}-0.067 \\
(0.286)\end{array}$ \\
\hline Crime, Age 18 & $\begin{array}{c}0.482 \\
(0.823)\end{array}$ & $\begin{array}{l}-0.089 \\
(0.418)\end{array}$ & $\begin{array}{l}-0.201 \\
(0.312)\end{array}$ \\
\hline Crime, Age 19 & $\begin{array}{c}0.622 \\
(0.593)\end{array}$ & $\begin{array}{c}1.032 * * \\
(0.437)\end{array}$ & $\begin{array}{c}0.817^{* *} \\
(0.341)\end{array}$ \\
\hline Obs. & 5,329 & 17,051 & 34,560 \\
\hline \multicolumn{4}{|l|}{ (B) 1991-1993 Cohorts } \\
\hline Grade 6 Reading Percentile & $\begin{array}{c}3.732 * * * \\
(0.751)\end{array}$ & $\begin{array}{c}4.797 * * * \\
(0.559)\end{array}$ & $\begin{array}{c}5.487 * * * \\
(0.450)\end{array}$ \\
\hline Grade 7 Reading Percentile & $\begin{array}{c}3.234^{* * *} \\
(0.730)\end{array}$ & $\begin{array}{c}4.187 * * * \\
(0.637)\end{array}$ & $\begin{array}{c}4.700 * * * \\
(0.503)\end{array}$ \\
\hline Grade 8 Reading Percentile & $\begin{array}{c}2.520 * * * \\
(0.813)\end{array}$ & $\begin{array}{c}3.522 * * * \\
(0.745)\end{array}$ & $\begin{array}{c}4.178 * * * \\
(0.580)\end{array}$ \\
\hline Grade Retention, Age 11-15 & $\begin{array}{c}-4.118^{* * *} \\
(0.467)\end{array}$ & $\begin{array}{c}-4.977 * * * \\
(0.437)\end{array}$ & $\begin{array}{c}-5.588 * * * \\
(0.400)\end{array}$ \\
\hline Juvenile Offense, Age 13-15 & $\begin{array}{c}0.052 \\
(1.014)\end{array}$ & $\begin{array}{c}-2.321^{* * *} \\
(0.845)\end{array}$ & $\begin{array}{c}-2.803^{* * *} \\
(0.571)\end{array}$ \\
\hline Juvenile Offense, Age 13 & $\begin{array}{l}-0.124 \\
(0.494)\end{array}$ & $\begin{array}{c}-0.534 \\
(0.425)\end{array}$ & $\begin{array}{l}-0.443 \\
(0.316)\end{array}$ \\
\hline Juvenile Offense, Age 14 & $\begin{array}{l}-0.292 \\
(0.813)\end{array}$ & $\begin{array}{c}-1.342 * * \\
(0.593)\end{array}$ & $\begin{array}{c}-1.474 * * * \\
(0.394)\end{array}$ \\
\hline Juvenile Offense, Age 15 & $\begin{array}{c}0.435 \\
(0.538)\end{array}$ & $\begin{array}{c}-1.434^{* *} \\
(0.548)\end{array}$ & $\begin{array}{c}-1.774 * * * \\
(0.394)\end{array}$ \\
\hline Obs. & 8,579 & 26,922 & 54,416 \\
\hline
\end{tabular}

Note: ${ }^{* * *} \mathrm{p}<0.01,{ }^{* *} \mathrm{p}<0.05,{ }^{*} \mathrm{p}<0.1$. Robust standard errors clustered at the birthday level are in parentheses. Each entry refers to the discontinuity estimate obtained for the given outcome (rows) and 
bandwidth (column). All regression specifications include birthdays (R), post-cutoff indicator (D) and its interaction term (DR), as well as other individual covariates and cohort-fixed effects. 
Table 12: Exposure to Legal Dropout, High School Attainment and Crime

\begin{tabular}{|c|c|c|c|c|c|c|}
\hline \multirow{3}{*}{$\begin{array}{l}\text { Cohort: } \\
\text { Sample: } \\
\text { Enrollment, Year } 12\end{array}$} & \multicolumn{3}{|c|}{ 1987-1988 } & \multicolumn{3}{|c|}{ 1991-1993 } \\
\hline & \multicolumn{2}{|c|}{ "On-time" } & \multirow{2}{*}{$\begin{array}{c}\text { Full } \\
-4.448^{* * *} \\
(0.773)\end{array}$} & \multicolumn{2}{|c|}{ "On-time" } & \multirow[t]{2}{*}{ Full } \\
\hline & $\begin{array}{c}-10.377 * * * \\
(0.771)\end{array}$ & $\begin{array}{c}-10.136^{* * *} \\
(0.755)\end{array}$ & & & & \\
\hline Crime, Age 17-19 & $\begin{array}{c}1.046 * * \\
(0.506)\end{array}$ & $\begin{array}{c}1.035^{* *} \\
(0.501)\end{array}$ & $\begin{array}{l}0.851^{*} \\
(0.469)\end{array}$ & & & \\
\hline Delinquency, Age 13-15 & & & & $\begin{array}{c}-2.366^{* * *} \\
(0.687)\end{array}$ & $\begin{array}{c}-2.509 * * * \\
(0.674)\end{array}$ & $\begin{array}{c}-2.803^{* * *} \\
(0.571)\end{array}$ \\
\hline Reading Score, Age 11 & No & Yes & No & No & Yes & No \\
\hline Obs. & 27,486 & 27,486 & 34,560 & 41,188 & 41,188 & 54,418 \\
\hline
\end{tabular}

Note: Each entry refers to the discontinuity estimate obtained for the given outcome (rows), birth cohort (columns) and sample group (columns). Full sample refers to those born in North Carolina and attended its public schools between ages 11 and 15 (See Tables 4, 5, and 6). "On-time" sample restricts the main sample to those who were placed in the predicted grade level at age 11. Robust standard errors clustered at the birthday level are in parentheses. ${ }^{* * *} \mathrm{p}<0.01,{ }^{* *} \mathrm{p}<0.05$, ${ }^{*} \mathrm{p}<0.1$. All regression specifications include birthdays (R), post-cutoff indicator (D) and its interaction term (DR), as well as other individual covariates and cohort-fixed effects. 
Figure 1: Grade Level Distribution across Age Levels, 1987 Cohort

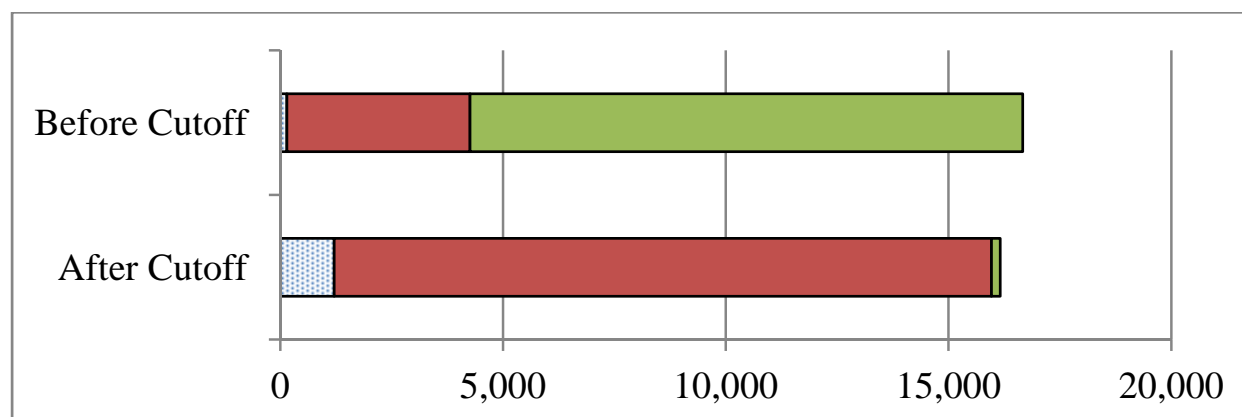

๑ Grade at Age $11=4 \quad \square$ Grade at Age $11=5 \square$ Grade at Age $11=6$

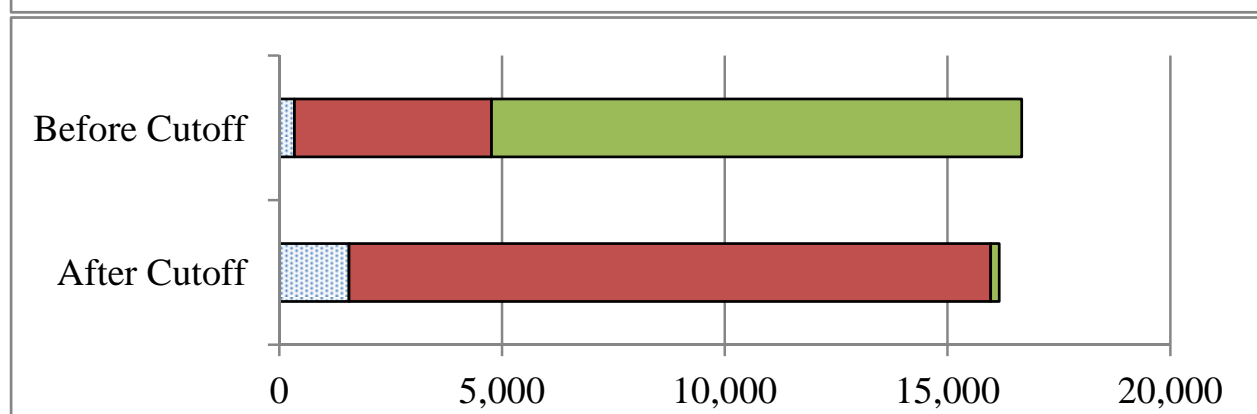

๑ Grade at Age $13=6 \square$ Grade at Age $13=7 \quad \square$ Grade at Age $13=8$

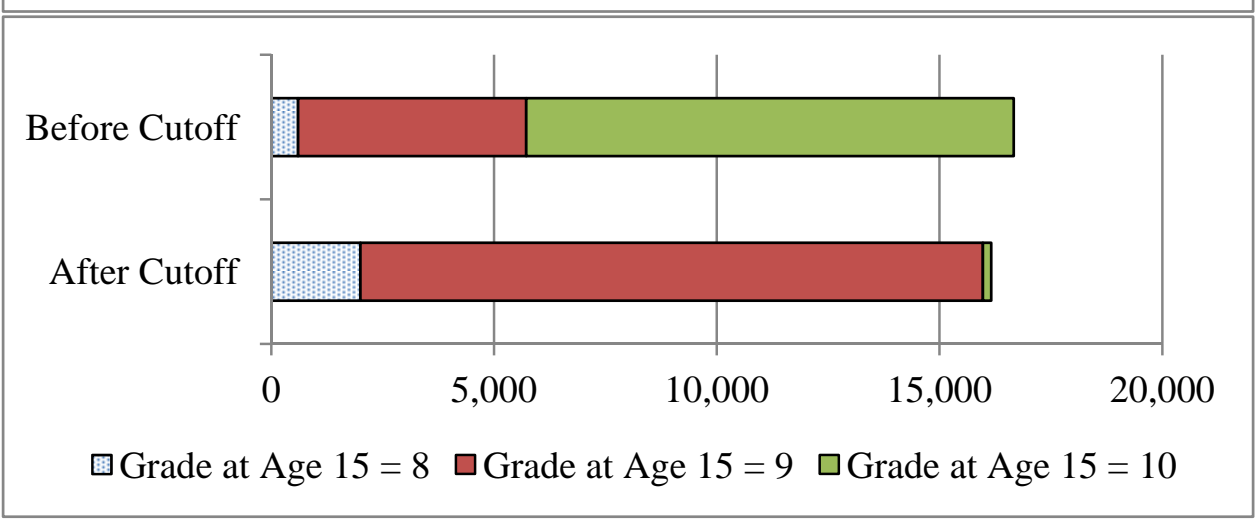

Note: Figure is based on cohorts of students who were born in North Carolina within 120 days of the school entry cutoff date in 1987 (October 17) and attended NC public schools between age 11 and 15. 
Figure 2: Grade Level Distribution at Age 11, 1987-1988 Cohort

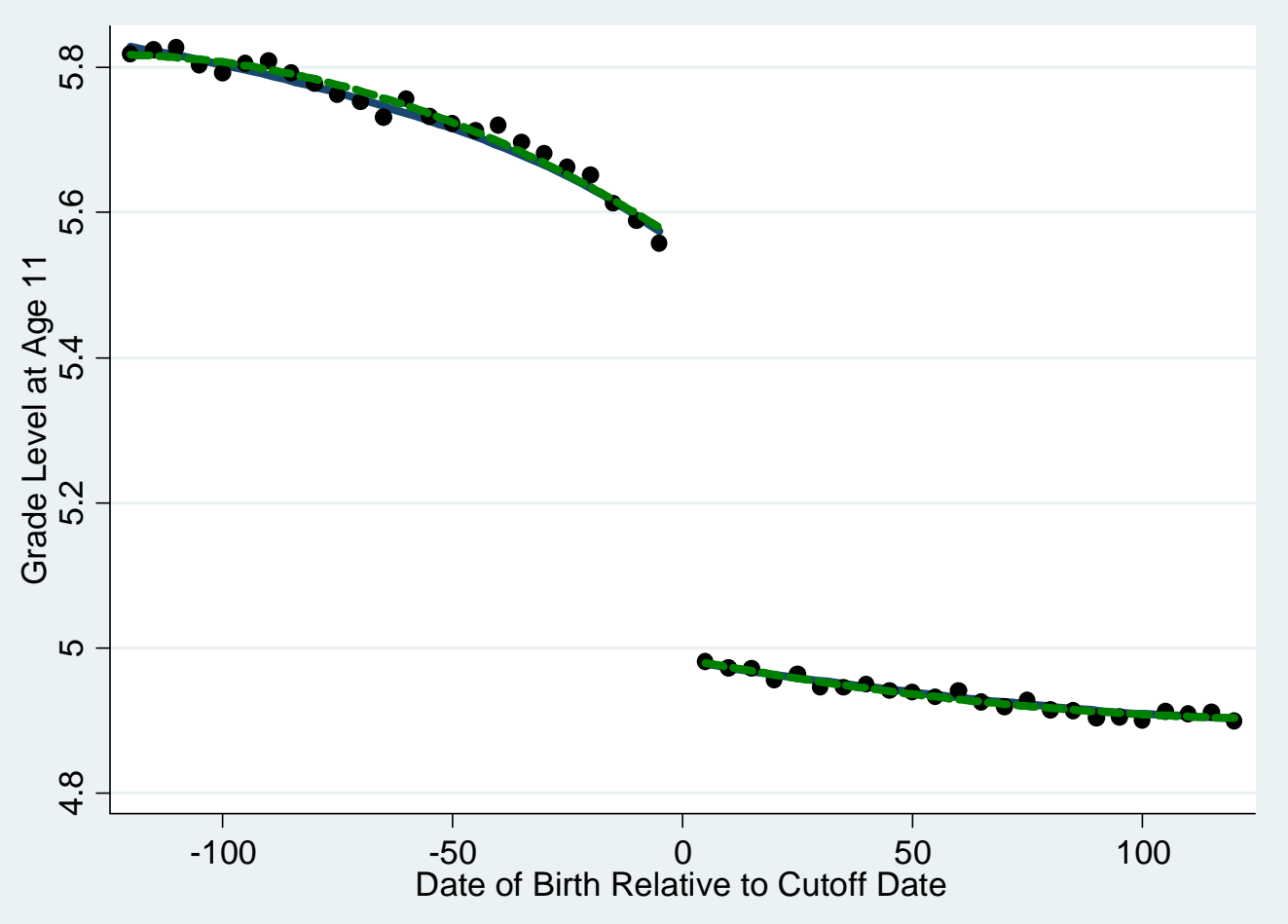

Note: Figure is based on cohorts of students born around the school entry cutoff dates in 1987 and 1988. Each cohort is defined by students born between June 19 of the given year and February 14 of the following year (120 days before and after the cutoff date of October 17 (= Day 0), respectively). The sample is further restricted to students 1) who attended NC public schools between age 11 and 15, 2) whose NC birth certificate information is available. $N=69,572$. Horizontal axis represents the date of birth relative to the cutoff date. Dots represent 5-day averages of students' grade level at age 11. Solid curves represent local linear smoother using a triangle kernel and 60-day bandwidth, and dashed curves represent quadratic fits, computed separately for children born before and after the cutoff date. 
Figure 3: EOG Reading Score Percentiles in Grades 6 through 8, 1987-1988 Cohort
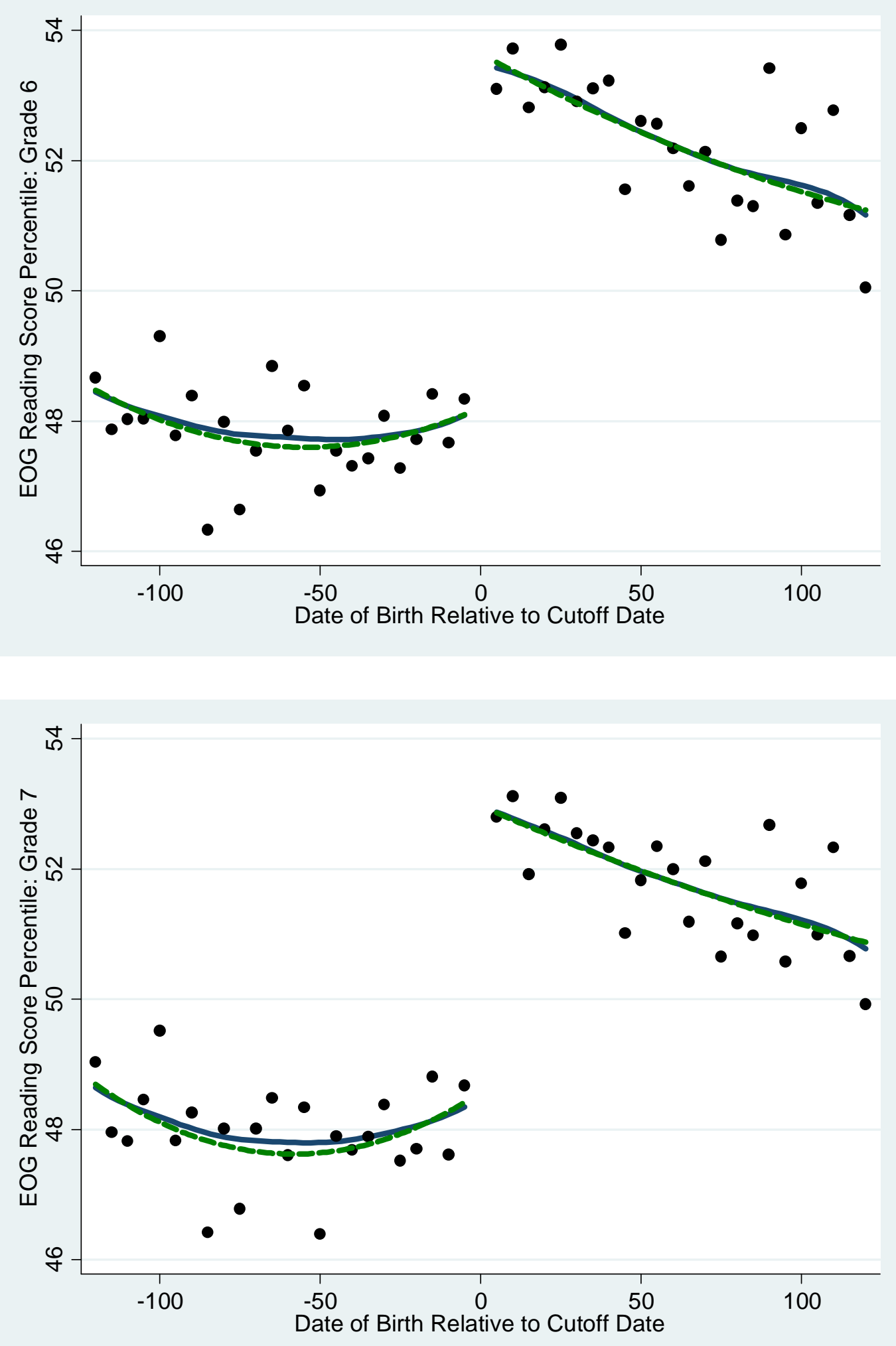


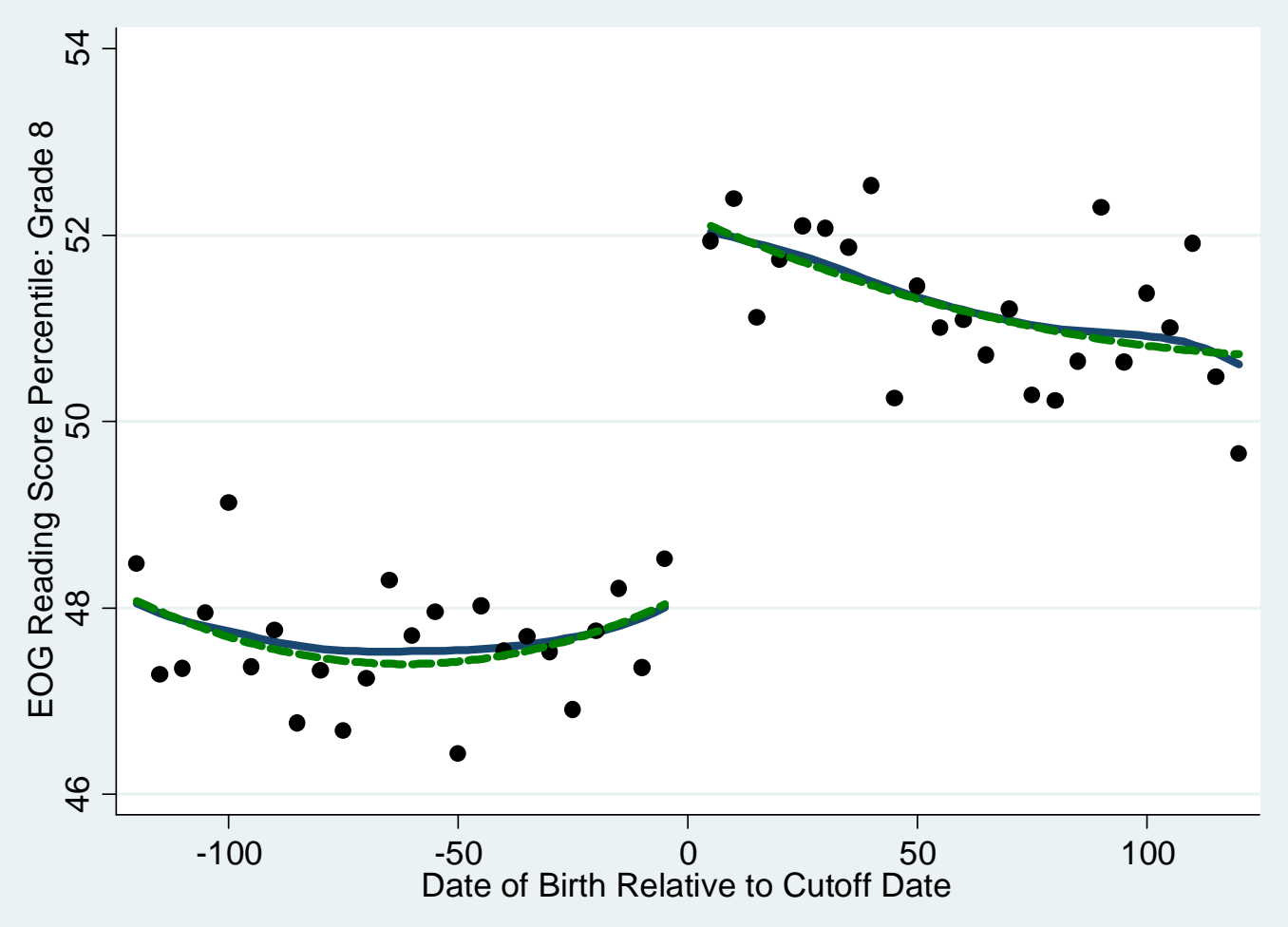

Note: Figure is based on cohorts of students born around the school entry cutoff dates in 1987 and 1988. Each cohort is defined by students born between June 19 of the given year and February 14 of the following year (120 days before and after the cutoff date of October 17 (= Day 0), respectively). The sample is further restricted to students 1) who attended NC public schools between age 11 and 15, 2) whose NC birth certificate information is available. $N=69,572$. Horizontal axis represents the date of birth relative to the cutoff date. Dots represent the EOG reading score percentile (normalized with respect to each grade level and test year), averaged over 5-day blocks. Solid curves represent local linear smoother using a triangle kernel and 60-day bandwidth, and dashed curves represent quadratic fits, computed separately for children born before and after the cutoff date. 
Figure 4: EOG Math Score Percentiles in Grades 6 through 8, 1987-1988 Cohort
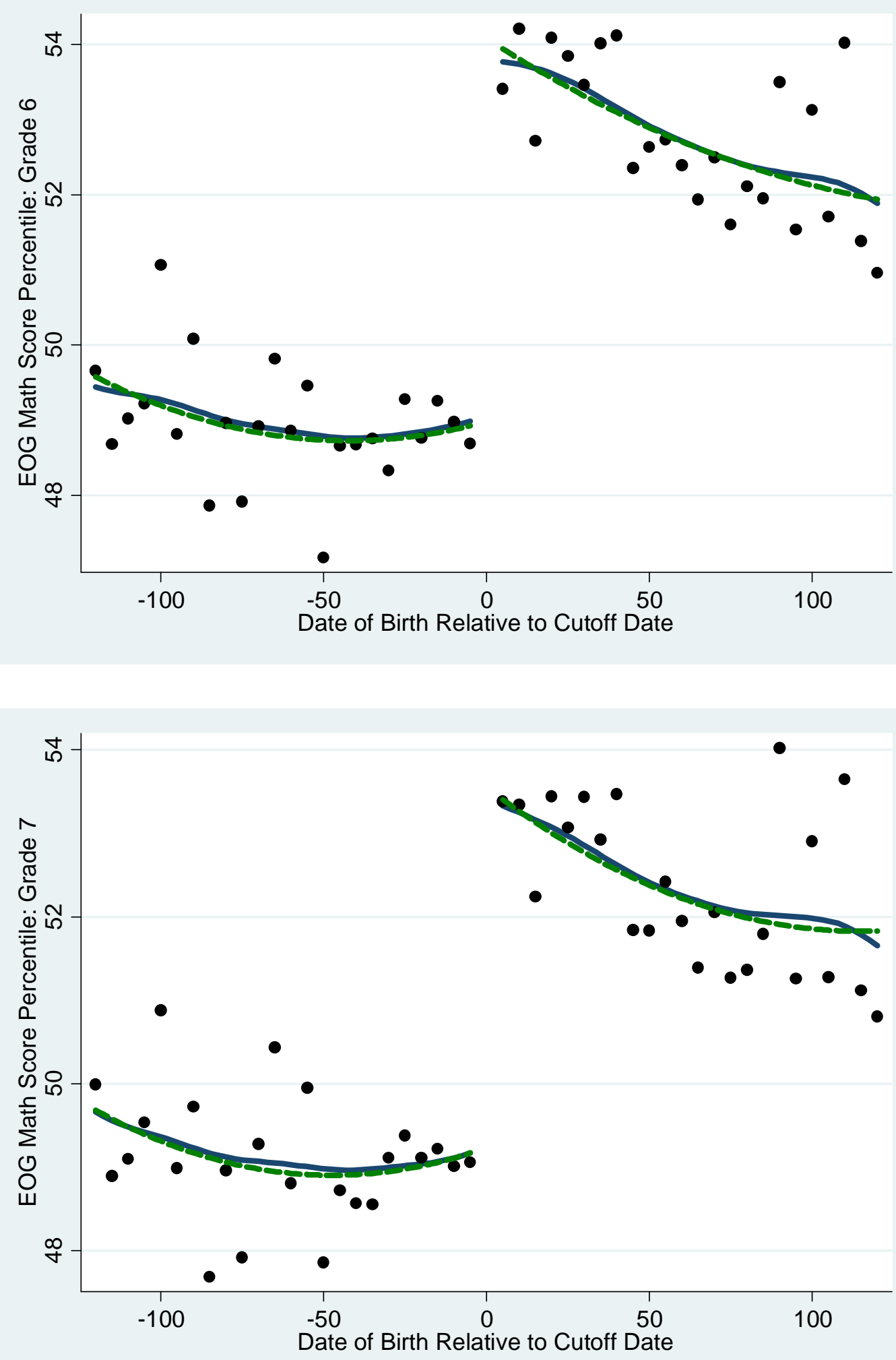


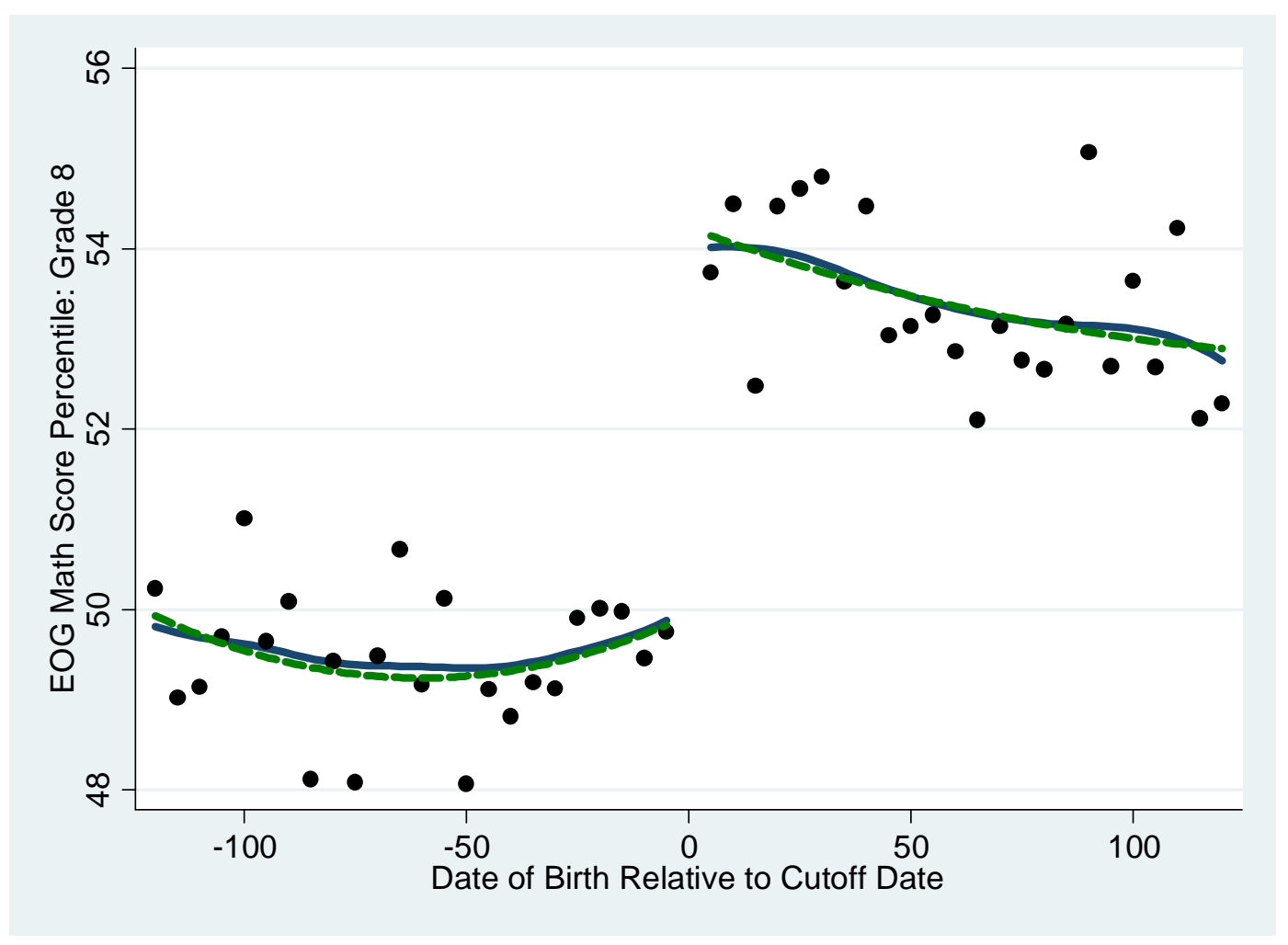

Note: Figure is based on cohorts of students born around the school entry cutoff dates in 1987 and 1988. Each cohort is defined by students born between June 19 of the given year and February 14 of the following year (120 days before and after the cutoff date of October 17 (= Day 0), respectively). The sample is further restricted to students 1) who attended NC public schools between age 11 and 15, 2) whose NC birth certificate information is available. $\mathrm{N}=69,572$. Horizontal axis represents the date of birth relative to the cutoff date. Dots represent the EOG math score percentile (normalized with respect to each grade level and test year), averaged over 5-day blocks. Solid curves represent local linear smoother using a triangle kernel and 60-day bandwidth, and dashed curves represent quadratic fits, computed separately for children born before and after the cutoff date. 
Figure 5: Share of Students Repeating Grades between Age 11-15, 1987-1988 Cohort

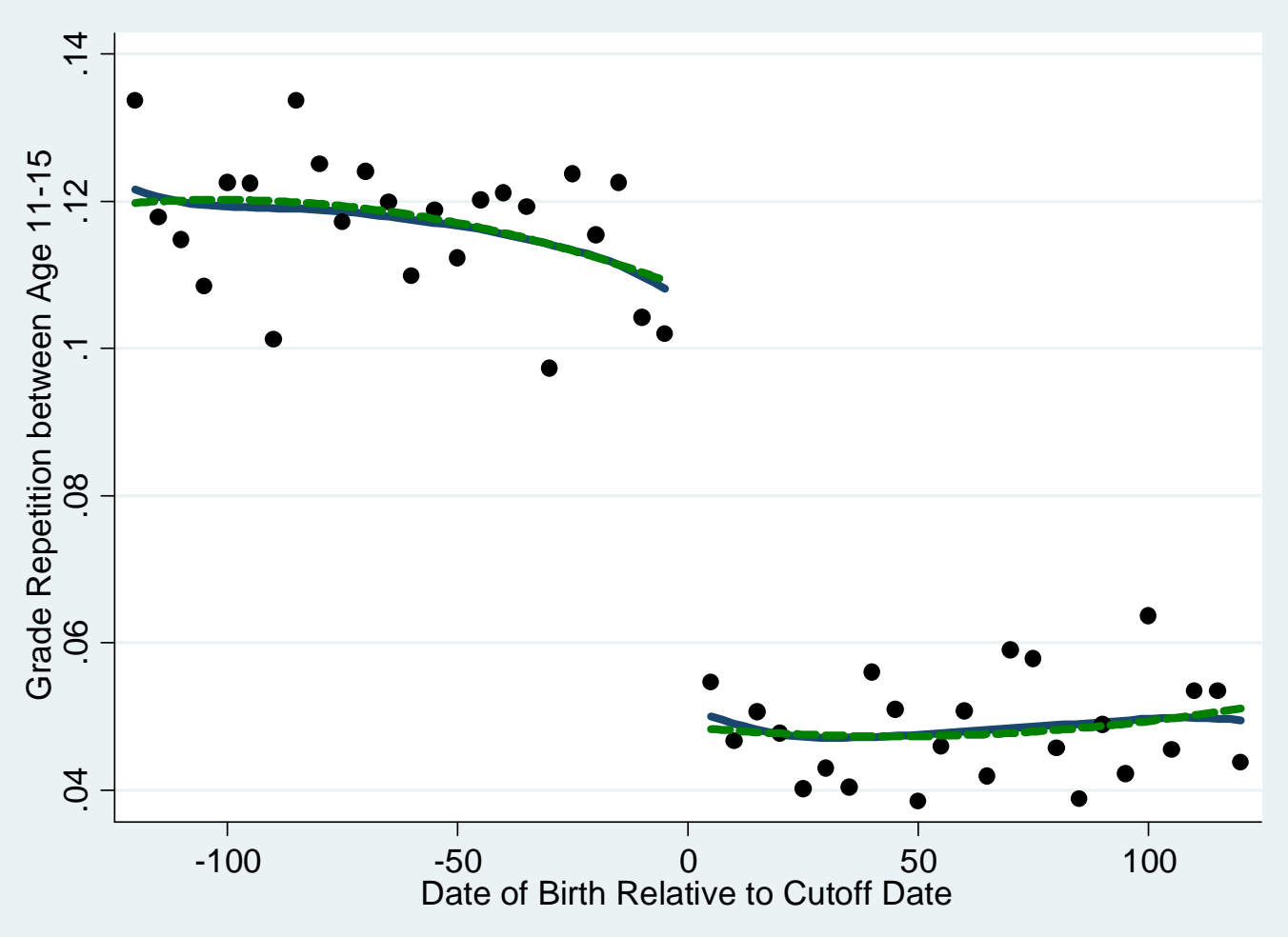

Note: Figure is based on cohorts of students born around the school entry cutoff dates in 1987 and 1988. Each cohort is defined by students born between June 19 of the given year and February 14 of the following year (120 days before and after the cutoff date of October 17 (= Day 0), respectively). The sample is further restricted to students 1) who attended NC public schools between age 11 and 15, 2) whose NC birth certificate information is available. $\mathrm{N}=69,572$. Horizontal axis represents the date of birth relative to the cutoff date. Dots represent 5-day averages of the share of students repeating grades between ages 11 and 15. Solid curves represent local linear smoother using a triangle kernel and 60-day bandwidth, and dashed curves represent quadratic fits, computed separately for children born before and after the cutoff date. 
Figure 6: Share of Students Enrolled in School in Years 11 and 12, 1987-1988 Cohort
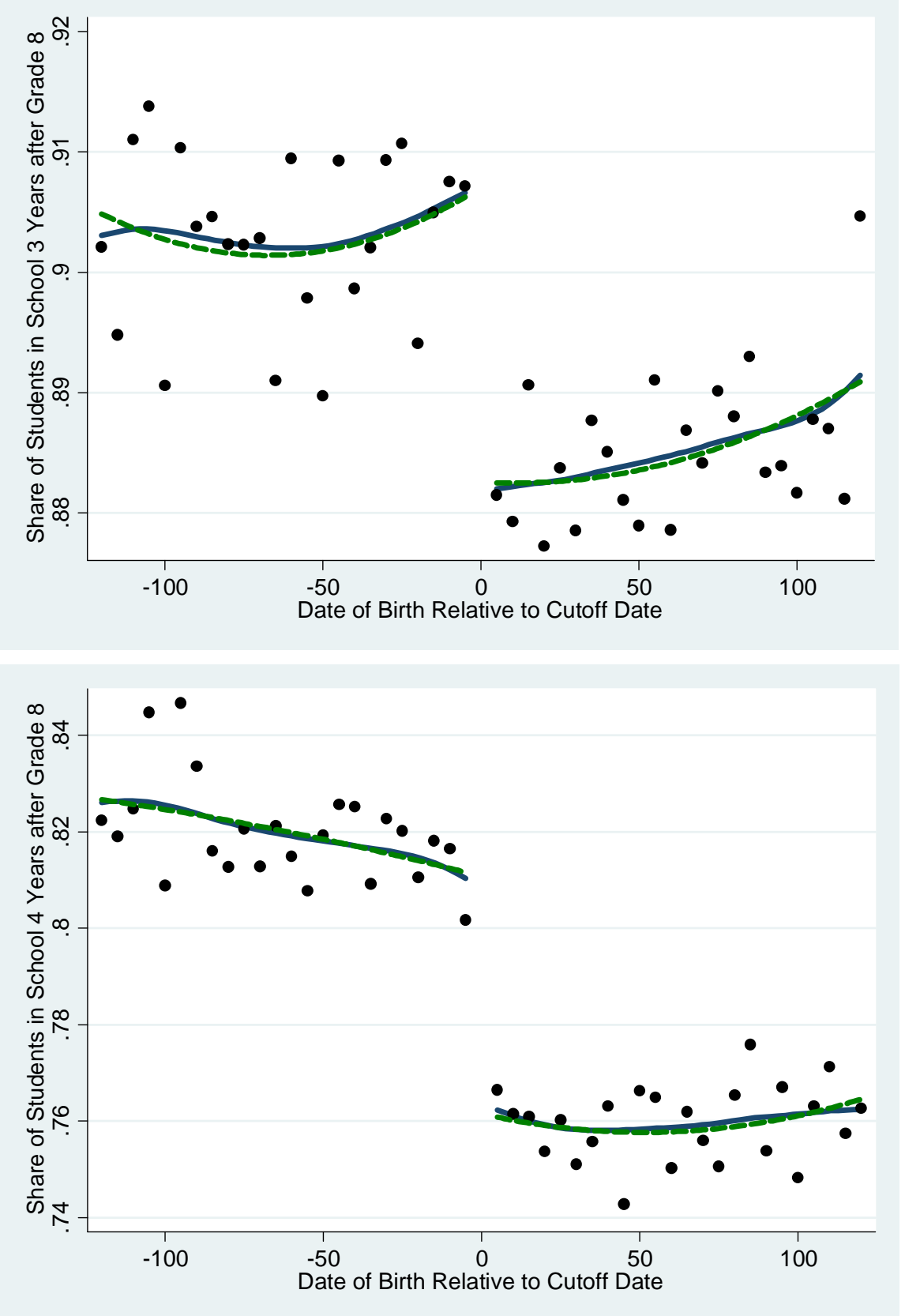

Note: Figure is based on cohorts of students born around the school entry cutoff dates in 1987 and 1988. Each cohort is defined by students born between June 19 of the given year and February 14 of the following year (120 days before and after the cutoff date of October 17 (= Day 0), respectively). The sample is further restricted to students 1) who attended NC public schools between age 11 and 15, 2) whose NC birth certificate information is available. $N=69,572$. Horizontal axis represents the date of birth relative to the cutoff date. Dots represent 5-day averages of the share of students who remain enrolled in NC public school 3 and 4 years after grade 8 ("Year 11" and "Year 12"). Solid curves represent local linear smoother using a triangle kernel and 60-day bandwidth, and dashed curves represent quadratic fits, computed separately for children born before and after the cutoff date. 
Figure 7: Share of Students Placed in the Grade Level Predicted by Their Birthdays, 1987-1988 Cohort

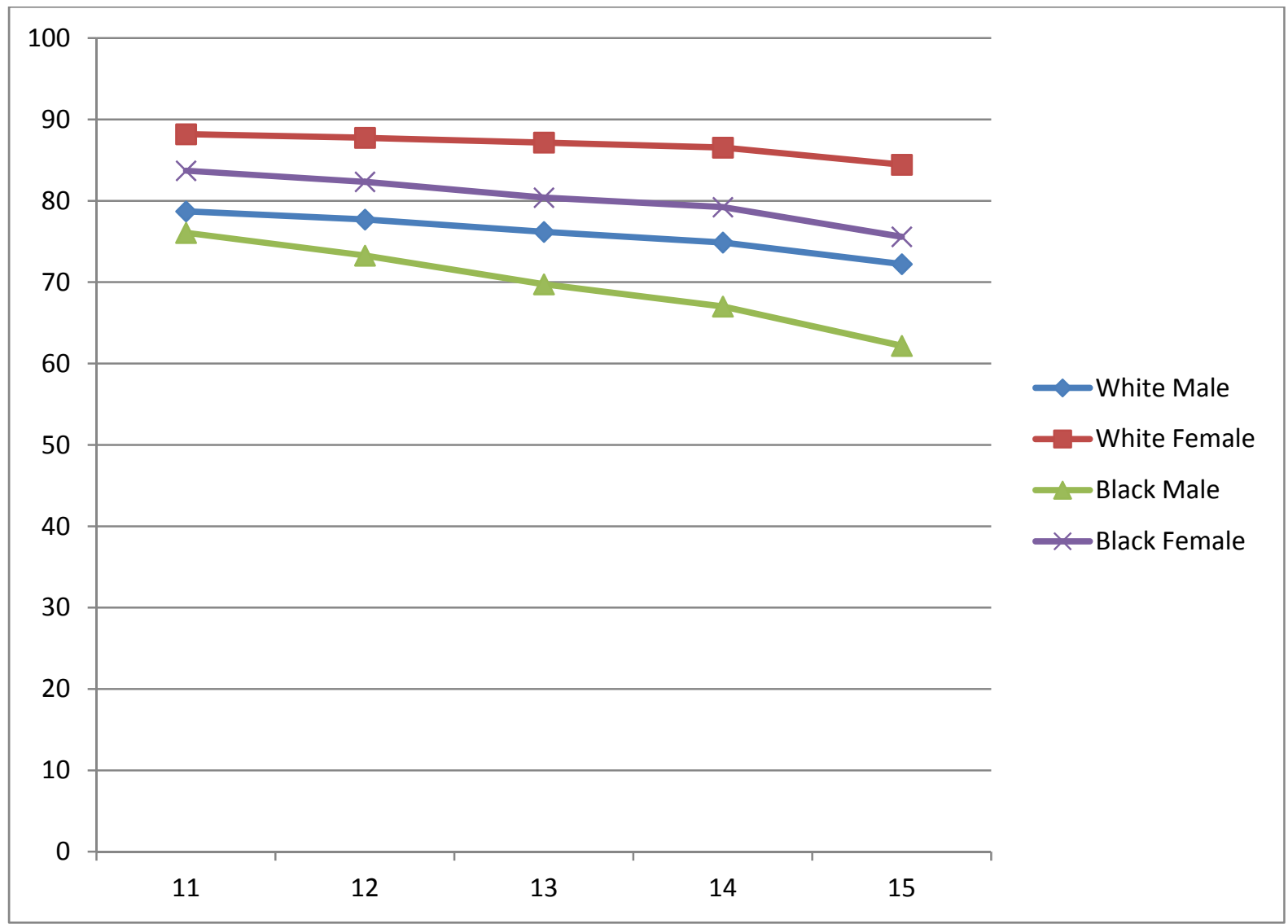

Note: Horizontal axis corresponds to the age at which on-time grade progress is measured. Vertical axis represents the percentage of students placed in the grade level predicted by their birthdays. 
Figure 8: Birth Frequency and Sample Attrition Rate
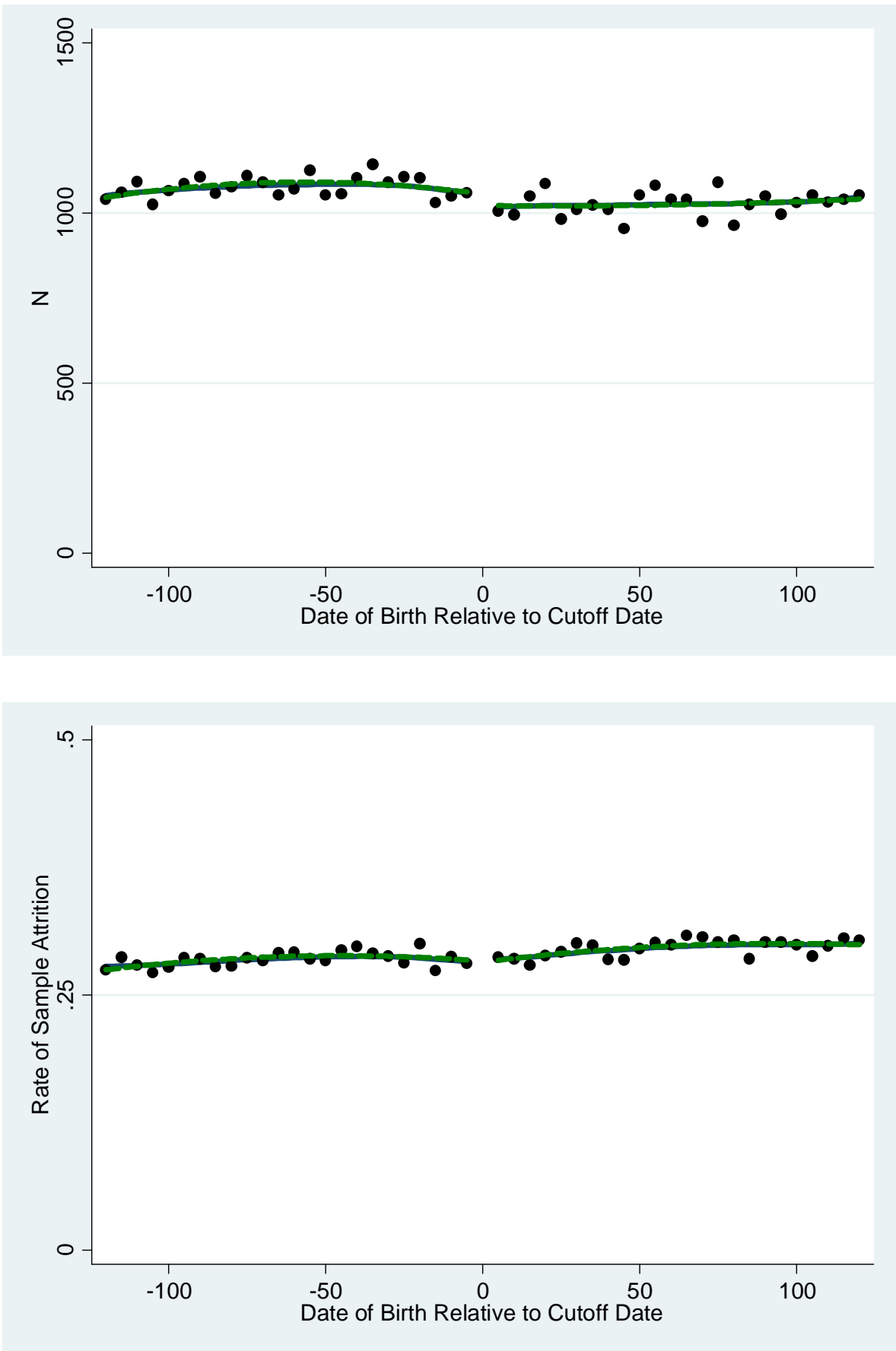

Note: Horizontal axis represents the date of birth relative to the cutoff date. Dots represent 5-day averages of birth frequencies and sample attrition rates across five cohorts (1987, 1988, 1991, 1992 and 1993). Solid curves represent local linear smoother using a triangle kernel and 60-day bandwidth, and dashed curves represent quadratic fits, computed separately for children born before and after the cutoff date. 
Table A.1: "Rule-of-Thumb” (ROT) Bandwidth Choices

\begin{tabular}{lcccc}
\hline \hline Cohorts: & \multicolumn{2}{c}{ 1987-1988 } & \multicolumn{2}{c}{ 1991-1993 } \\
Direction: & Left & Right & Left & Right \\
\hline EOG Reading, Grade 6 & 17 & 12 & 16 & 14 \\
EOG Reading, Grade 7 & 10 & 18 & 13 & 11 \\
EOG Reading, Grade 8 & 17 & 12 & 18 & 10 \\
Grade Retention, Age 11-15 & 13 & 10 & 7 & 13 \\
On-time Progress, Age 15 & 13 & 15 & 12 & 26 \\
Enrollment, Year 12 & 9 & 13 & & \\
Crime, Age 17 & 17 & 12 & & \\
Crime, Age 18 & 14 & 8 & & \\
Crime, Age 19 & 12 & 9 & & \\
Delinquency, Age 13 & & & 8 & 24 \\
Delinquency, Age 14 & & & 9 & 8 \\
Delinquency, Age 15 & & & 7 & 7 \\
\hline
\end{tabular}

Note: The ROT procedure is based on the fourth-order global polynomial approximation. First, we regress each outcome of interest (rows) on the fourth-order polynomial of birthdays. Then, the ROT bandwidth is equal to $C=\left[\frac{\sigma^{2} R}{\sum_{i=1}^{N}\left\{m^{\prime \prime}\left(x_{i}\right)^{2}\right\}}\right]$, where $\mathrm{C}=3.438$ is a constant for the triangular kernel, $\sigma^{2}$ is the estimated standard error of the regression, $\mathrm{R}$ is the range of the assignment variable, and $\left\{m^{\prime \prime}\left(x_{i}\right)^{2}\right\}$ is the second-derivative of the fourth-order polynomial. This process is done separately on the left and right sides of the cutoff point. See Fan and Gjibels (1996) for details. 